\title{
ACKNOWLEDGEMENT
}

The author wishes to express his indebtedness to Professor T. Salman for his guidance and patience in directing this research investigation, and to the National Research Council for a grant to study surface phenomena.

Thanks are due to Mr. W. Bishop of Hercules Powder Company, whose interest in the project proved very helpful. Also to Mr. L. Sirois and Dr. T. Takamori, of the Mines Branch, whose critical review of the results and the manuscript was of very great assistance. 


\section{ADSORPTION OF DEHYDROABIETYLAMINE ACETATE ON QUARTZ AND HEMATITE}

By

N. NEMETH

A the sls submitted to the Faculty of Graduate

Studles and Research in partlal fulfillment of the requlrements for the degree of Master of Engineering.

McGlll University,

Montreal, Canada

August, 1964. 


\section{ACKNOWLEDGEMENTS}

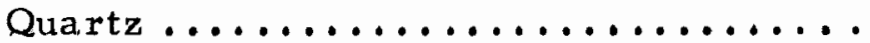

Hematite .................... 9

Dehydroabietylamine Acetate ........ 10

Haultain Infrasizer ............. 12

Screens ...................... 12

Spectrophotometer .............. 12

Adsorption Column ............... 12

B.E.T. Apparatus ............ 12

Quartz ..................... 13

Hematite ................... 13

Acetate Solutions ............... 14

Adsorption Time ............... 14

Adsorption Column .............. 15

VI $\quad$ EXPERIMENTAL RESULTS $\ldots \ldots \ldots \ldots \ldots \ldots$

Calculation of Surface Coverage $\ldots \ldots \ldots \quad 19$

VII DISCUSSION OF RESULTS $\ldots \ldots \ldots \ldots \ldots \ldots$

Adsorption in Near Neutral Solutions ... $\quad 28$

De sorption in Near-Neutral Solutions ... 31

Comparison of Adsorption in Near Neutral

Solutions............... 37

Comparison of Adsorption in Basic

Solutions .............. 40

Effect of $\mathrm{pH}$ on Adsorption at Constant 


\section{TABLE OF CONTENTS}

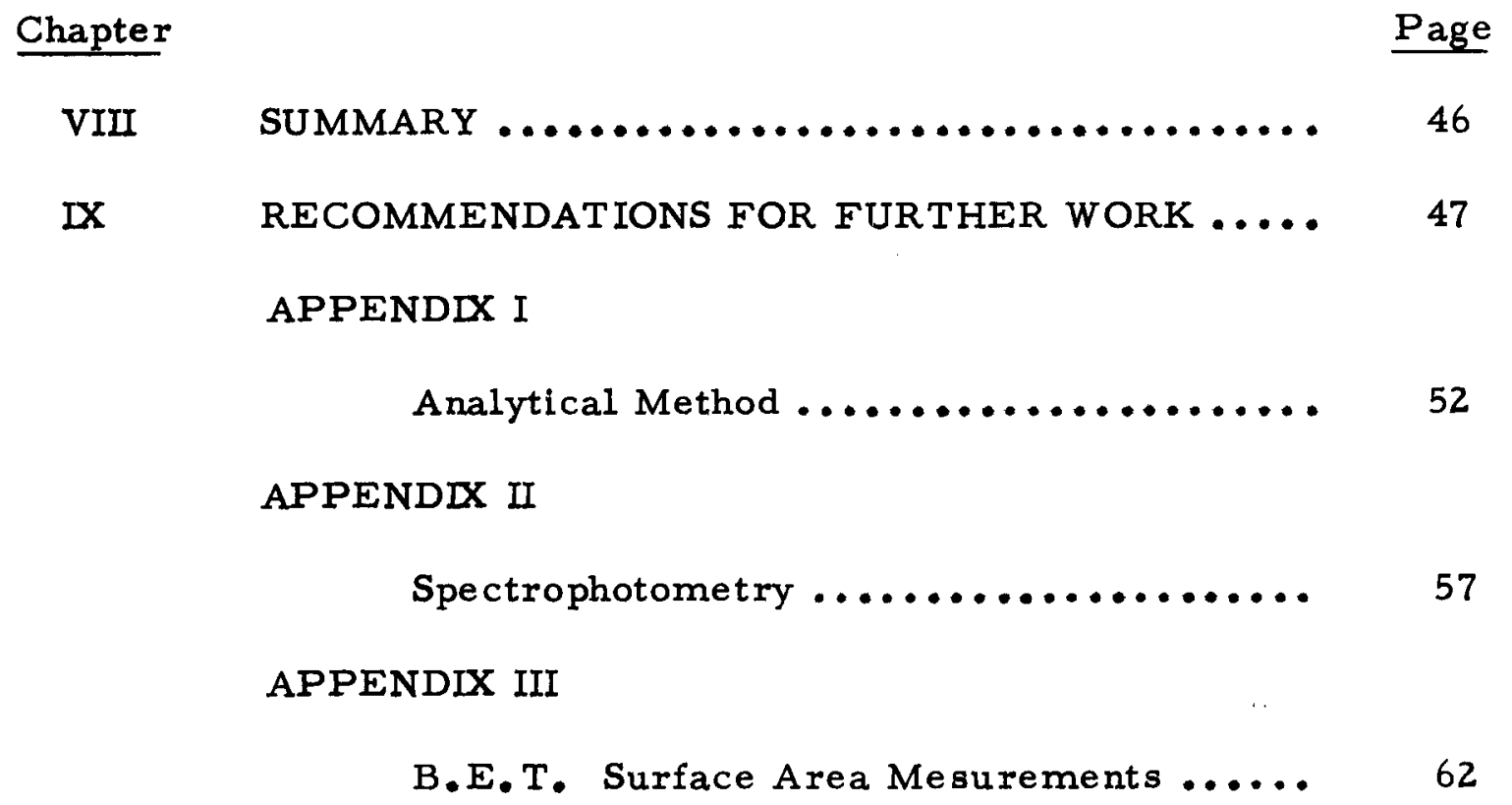


1 Adsorption of Dehydroabietylamine

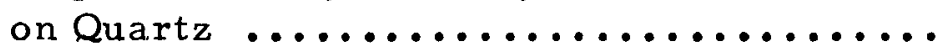

Adsorption of Dehydroabietylamine on

Hematite ...................... 21

Adsorption on Quartz in Basic Solution ....... 22

4 Adsorption on Hematite in Basic Solution ..... 23

5 Adsorption on Hematite with Changing pH ..... 24

6 Adsorption on Silica with Changing $\mathrm{pH} \quad \ldots \ldots \ldots .25$

7 Adsorption Data on Quartz in Near-Neutral

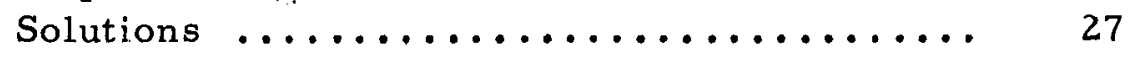




\section{LIST OF ILLUSTRATIONS}

\begin{tabular}{|c|c|c|}
\hline Figure & & Page \\
\hline 1 & Adsorption Column .............. & 16 \\
\hline 2 & Adsorption-Desorption on Quartz ... . & 29 \\
\hline 3 & The Electrical double-layer $\ldots \ldots \ldots$ & 33 \\
\hline 4 & Adsorption in Near Neutral Solution... & 38 \\
\hline 5 & Adsorption in Basic Solutions ........ & 41 \\
\hline 6 & Variation of Adsorption with $\mathrm{pH} . \ldots$. . & 43 \\
\hline 7 & $\begin{array}{l}\text { Calibration Curve for the } \\
\text { Spectrophotometer... }\end{array}$ & 56 \\
\hline 8 & $\begin{array}{l}\text { Optical System of the Model Du } \\
\text { Spectrophotometer }\end{array}$ & 60 \\
\hline 9 & Surface of Hematite $\ldots \ldots \ldots \ldots \ldots \ldots$ & 70 \\
\hline 10 & Surface Area of Quartz .......... & 71 \\
\hline
\end{tabular}




\section{ACKNOWLEDGEMENT}

The author wishes to express his indebtedness to

Professor T. Salman for his guidance and patience in directing this research investigation.

Thanks are due to $\mathrm{Mr}$. W, Bishop of Hercules Powder Company, whose interest in the project proved very helpful. Also to Mr. L. Sirois and Dr. T. Takamori, of the Mines Branch, whose critical review of the results and the manuscript was of very great assistance. 


\section{INTRODUCTION}

Froth flotation is based on the differences in the physico-chemical surface properties of particles of various minerals. It is very seldom that the mineral to be separated possesses the desirable surface characteristics. Outside intervention is required to alter the natural surface of the mineral particles that make up the flotation pulp. The mineral that is to be floated by attachment to an air bubble must have a hydrophobic surface and the rest of the pulp must be hydrophilic or easily wettable. A mineral surface can be rendered hydrophobic by the attachment of a laye r built up of long chain hydrocarbons or of inert organic substances.

Adsorption describes the phenomenon of attachment of these substances to the mineral surfaces. There exists a variety of ways by which this attachment is possible. Organic substances can be adsorbed as ions, molecules or as multimolecular units. Consequently, the factors that influence adsorption are the interatomic and molecular forces and they are essentially electrical in nature when applied to oxides.

The present study was designed to explore the field of cationic flotation of quartz by studying the adsorption behaviour of dehydroabietylam:.: ine acetate. Cationic flotation grew in importance as the need arose to concentrate large tonnages of low grade iron ores.

"Low grade iron ore" is usually defined as an ore with an $\mathrm{SiO}_{2}$ content higher than $14 \%$, but is rather loosely used in connection with all ores that require some treatment before shipment to the furnaces. 
Flotation can be applied to the se low grade iron ores by following one of the four processes:

(1) Anionic collection of iron oxides

(2) Cationic collection of iron oxides at proper $\mathrm{PH}$ values

(3) Cationic collection of siliceous gangue - often referred to as reverse flotation, and

(4) Anionic collection of activated siliceous gangue. (1)

The method that is most suitable to treat a particular ore is evaluated on the basis of economy; cost of reagents, cost of preparation and handling, and the effect of the altered surface characteristics in successive treatments.

Although the feasibility of oxide flotation was established for some time, theoretical investigations into the mechanism of the process are of recent origin. Most of the research work on cationic collection and adsorption properties were done using a straight chain hydrocarbon reagent. The most frequently studied collectors were dodecylamine derivatives.

Basically, there are two distinct adsorption phenomena: physical adsorption and chemisorption. In practice the two processes are not so distinctly removed from one another. As Glembotskii stated it (11):

"Among the adsorption phenomena of dissolved substances by! sol;id sunfaces thiere is a multiplicity of adsorption processes, representing an almost unbroken 
transition from physical to chemical adsorption."

The prominent feature common to chemisorption and physical adsorption is that they are both spontaneous, each being accompanied by a loss of free energy and the release of a definite amount of heat.

The difference between them is that in chemisorption the adsorbed substance and the crystal lattice present a unified energy relationship. In physical adsorption, the adsorbed substance and the crystal lattice remain as two independent systems. The attachment of an atom to the mineral lattice and the bond between them in chemisorption is due to a transmission of electrons from the adsorbed atom to the lattice and vice versa. In physical adsorption the corresponding bond is maintained by the much weaker Van der Waals forces. Furthermore, heat effects accompanying chemisorption are greater than the heats of physical adsorption. Chemical adsorption shows a very marked selectivity that is lacking in physical adsorption. A remarkable characteristic of physical adsorption is the fast xate at which it establishes equilibrium between the solid surface and the aqueous solution. As a result of the low degree of selectivity, physical adsorption produces a more even surface coverage than is found in chemical adsorption.

There are a number of ways of attaching dissolved substances to solid surfaces. The more typical ones are:

(1) Attachment in the electric double layer.

The number of ions that can be adsorbed in the electrical double layer will be determined by the surface charge of the mineral. 
In the diffused part of the outer layer, ions of any size or nature can be adsorbed, provided the sign of these ions is the same as the ions of the fixed part of the outer layer. If a solution contains ions of various elements, and they can all be adsorbed in the diffused part due to their identical charge, then the degree of adsorption of each ion will be directly proportional to the concentration of the se ions in the solution. Attachment of ions in the outer layer involves the participation of electrical attraction and repulsion forces between the ions operating over considerable distances. Ions of flotation reagents adsorbed in the diffused layer represent an unstable state and they can be easily desorbed. (2) Attachment to the minerals in the form of surface compounds. This form of adsorption is very common in flotation. The main feature of the process is that the surface compounds do not form separate phases that can exist independently. The ions or atoms of the mineral crystal lattice which participate in the formation of the surface compounds expend only part of their bond energy on this process and remain connected to the other atoms or ions in the lattice as before. A peculiarity of surface compounds is the absence of a stoichiometric relationship in ions or atoms forming these compounds. This is due to the fact that the atoms or ions which form part of their structures exist as a whole with all the atoms or ions in the crystal lattice of the solid body. Surface compounds can be regarded as radicals attached to parts of the surface of a solid body and capable of existing only in conjunction with this surface, not as substances having a definite composition. 
Reagent a.ttachment to the mineral aurface in the form of films.

Very often adsorption takes the form of attachment of a

film onto the solid surface. Usually, the film is a three dimensional growth on the mineral surface. It is an entirely independent state that can exist as such. Films are important in flotation, because their appearance on the mineral surface changes the flotation properties of that mineral.

The formation of a film on a mineral surface is determined the rmodynamically by the fact that the nucleus of a new crystalline solid phase can always develop more easily on a phase interface than in the body of a solution. Strength of attachment depends on the relationship between the film crystal lattice parameters and those of the minerals, on which it develops. The rate of film formation is increased by raising the temperature and mixing the pulp. Where the film is not attached firmly enough to the mineral surface, mechanical agitation may affect the process adversely by causing the film to peel off.

Oxide surfaces are known to have negative surface charges in solutions of proper $\mathrm{pH}$. This necessitates a collector ion with a positive charge to adsorb and change the surface. Amine derivatives offer themselves as suitable compounds. The most important feature of cationic collectors is that their attachment is much weaker than that of the anionic collectors. Unfortunately, the actual workings of the attachment of cationic collectors to the mineral surface is not fully established yet. Results of investigations to date indicate that the reaction between the 
mineral surface and cationic collectors is based on physical adsorption, characterized by an unstable reversible state.

Iwasaki, Cooke and others (1), (5), (15) found that the collecting efficiency of cationic collectors is dependent on $\mathrm{pH}$ to a greater extent than anionic collectors. Cationic collecting action is limited over a comparatively narrow range of $\mathrm{pH}$ values which can be very moderately acidic - as for quartz - or moderately basic - as for iron oxides. 


\section{EXPERIMENTAL WORK}

Quartz and specular hematite were chosen to be the respective adsorbents in two simultaneously investigated systems. An apparent reason for this selection is that quartz is the most common gangue mineral in iron ores, and it was relatively easy to obtain high purity samples. The complete adsorption system was made up of the fine powdered sample - solid phase - and the aqueous solution of dehydronbietylamine acetate liquid phase. Adsorption occurs at the interface between the two phases and it can be determined by the concentration changes in the aqueous solution before and after adsorption.

Outline of the Investigation

(A) Preparation of test materials

(1) Sizing of quartz by the Houltain infrasizer

(2) Wet screening of hematite: $-270+400 \mathrm{M}$

(3) Cleaning of surfaces by dilute hydrochloric acid solution and subsequent washing with distilled water

(4) Preparation of a stock solution of dehydroabietylamine acetate

(B) Test procedures

(1) Determination of equilibrium adsorption times

(2) Concentration determination of solutions before and after adsorption

(3) pH measurements of test solutions

(4) Adsorption tests under various pH conditions

(C) Sirface area measurements by the B.E.T. method using Krypton gas for both samples. 


\section{TEST MATERIALS}

\section{Quartz}

Quartz is found in many forms. The most common variety

is $\alpha$ quartz that forms below $573^{\circ} \mathrm{C} . \alpha$ quartz is hexagonal-rhombohedral and commonly prismatic (26).

Quartz is an important constituent of igneous rock with an excess of silica, such as granite rhyolite pegmatite. An important property of quartz is its extremely high resistance to both mechanical and chemical wear.

Another occurrence of quartz is with metamorphic rocks, as gneisses and it is practically the only mineral of quartzites. Quartz is very often deposited from solutions and it is the most common vein and gangue mineral. As such it is found with all iron ore deposits, regardless of geographical location or genetic origin.

The sample used in these investigations was $\alpha$ quartz supplied by the Mines Branch in Ottawa. 


\section{Hematite}

A common occurrence of hematite is in the tabular or thin flake-like form. It often occurs micacens and foliated. This version is called specular hematite or specularite. Edges of plates may be bevelled with rhombohedral forms. Hematite sometimes occurs as distinct rhombohedral crystals - often with nearly cubic angles. The composition of pure hematite is $\mathrm{Fe}: 70 \% ; 0=30$ common impurities of hematite are $\mathrm{Ti}$ and $\mathrm{Mg}$.

Iron is the most abundant metal in the crust of the earth. Native state occurrence is very rare. Most commonly it is found as sulphides $\mathrm{FeS}_{2}$ or as oxides $\left.\mathrm{Fe}_{2} \mathrm{O}_{3}, \mathrm{Fe}_{3} \mathrm{O}_{4}, \mathrm{FeO}(\mathrm{OH})_{1} \mathrm{FeO}(\mathrm{OH}) \mathrm{m}_{2}\right) \mathrm{O}$ and as carbonate $\mathrm{FeCO}_{3}$. The most important ore minerals are the oxide types. Hematite is the most abundant ore of iron, occurring in a wide variety of forms: as contact metamorphic deposits, as metamorphosed ore bodies derived from the alteration of 1 imonite, siderite or magnetite and as irregular masses and beds as the result of weathering of iron bearing rocks.

The hematite used in the test work was obtained from the Labrador property of the Iron Ore Company of Canada as a spiral concentrate. 
(3)

Dehydroabietylamine is a high molecular weight amine derived from pine resin acids. The following graphic formula can be assigned to the principal constituent of this amine: (7)

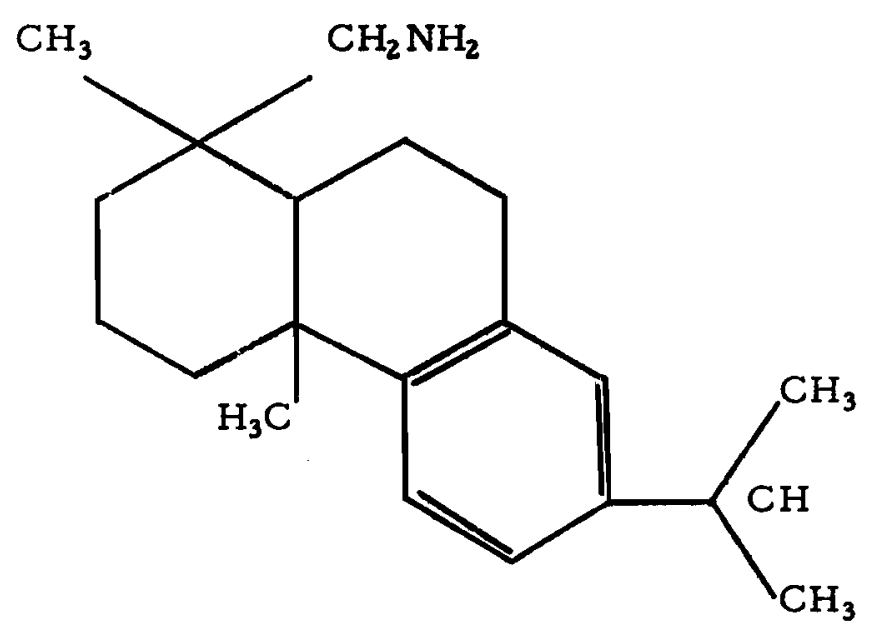

The general properties are as follows:

Colour, (Gardner):

6

Specific gravity at $25 / 15.6^{\circ} \mathrm{C}: \quad 0.999$

Refractive index @ 200 C: $\quad 1.5447$

Viscosity, poises at $25^{\circ} \mathrm{C}$ :

Secondary amine content $\% \quad 1.0$

Total amine content, $\%$

These amines are stable up to temperatures of $100^{\circ} \mathrm{C}$. Solubility: Dehydroabietylamine is practically insoluble in water. It is soluble in most common organic solvents including alcohols, ethers, hydrocarbons and chlorinated solvents. 


\section{Surface Activity:}

These pine resin amines facilitate the wetting of siliceous surfaces as illustrated by the following contact angle measurement data $(6)$.

Contact angle against glass immersed in water

$$
\begin{array}{lr}
\text { Mineral spirits alone } & 131^{\circ} \\
\text { Mineral spirits }+0.1 \% \text { amine D } & 114^{\circ} \\
\text { Mineral spirits }+1.0 \% \text { amine D } & 96^{\circ} \\
\text { Mineral spirits }+5 \% \text { amine D } & 77^{\circ}
\end{array}
$$

For the present adsorption study the acetic acid salt of dehydroabietylamine was used because it is easily soluble in water. High-purity dehydroabietylamine acetate was supplied by the Hercules Powder Co., and had the following composition (7).

$\begin{array}{lccc} & \frac{\text { Theoretical\% }}{\text { Carbon }} & & \text { Found\% } \\ \text { Hydrogen } & 76.47 & 76.72 \\ \text { Nitrogen } & 10.21 & 10.44 \\ \text { Direct Oxygen } & 4.05 & 3.95 \\ & \text { Total } & \frac{9.26}{99.99} & \frac{9.27}{100.38}\end{array}$

Based on this analysis the empirical formula was found to be: $\mathrm{C}_{22} \quad \mathrm{H}_{36} \quad \mathrm{NO}_{2}$ and the corresponding molecular weight is 346 . The molecular cross sectional area for the acid is $50 \mathrm{sq}$. Angstrom units and will be assumed to be the same for the amine (7), (8). 


\section{APPARATUS}

Haultain Infrasizer:

This apparatus was used to prepare a closely sized fraction of the fine quartz powder for the adsorption tests. Only the product from the 5 th cone was retained and used.

Screens:

The 270 mesh and the 400 mesh Tyler sieves were used to size the hematite sample.

Spectrophotometer:

A Beckman Du model spectrophotometer was used for the analytical work. The greatest advantage of this method was its speed and relative simplicity. Appendix 1 contains the detailed information regarding the analytical method and other relevant data. Adsorption Column:

The essential parts of the adsorption column included a $20 \mathrm{~mm}$ coarse friitzed glass filte $\mathrm{r}$ and a vacuum flask. The solution was introduced through a $250 \mathrm{ml}$ pyrex funnel. The arrangement is illustrated in Fig. 1.

B.E.T. Apparatus

This gas adsorption apparatus was used to determine the surface area of the samples, using Krypton as an adsorbate. (Appendix III) 


\section{PREPARATION OF TEST MATERIALS}

\section{Preparation of Samples:}

Quartz - 150 gram samples were infrasized for 3 hour periods. The material in cone number 5 was retained for the adsorption tests and the remaining cone products were rejected.

The samples of sized silica were cleaned in $1 \%$ solution of hydrochloric acid and washed thoroughly afterwards in distilled water to remove any traces of acid. When cleaning was completed, the silica was dried completely in a steam oven.

Smaller samples of quartz, ranging from 5 to 10 grams in weight, were split in a Carpco microsplitter. At the same time, a representative sample was obtained for B.E.T. surface area measurements.

\section{Hematite}

The original sample of hematite from Labrador contained a large amount of liberated silica. To obtain a pure sample the ore was tabled and the concentrate treated on a vanning plaque until there were no visible signs of silica in the sample. Purity was assured by microscopic examination and retreatment of the sample whenever it was necessary.

In addition to the silica a fairly large amount of magnetite was also found in the sample. Since the presence of magnetite could easily introduce anothe $r$ variable, it was removed by passing the concentrate through a Davis tube. The hematite that passed through the 
tube was checked again with a hand magnet and the sample retreated if any magnetite was found in it.

Final preparation and surface cleaning of the hematite was identical to that described for the quartz.

2. Preparation of the Dehydroabietylamine Acetate Solution

Stock solution containing 1 gram of the acetate per $100 \mathrm{ml}$ of solution was prepared. This represented a concentration of 10,000 part per million. From the stock solution other solutions of varying concentrations could be made up for the adsorption tests.

The spectrophotographic calibration curve for dehydroabietylamine acetate was found by using $5,10,15$ and $20 \mathrm{mg} / \mathrm{liter}$ concentrations, prepared with the greatest possible accuracy.

\section{Determination of Adsorption Time}

Before embarking on a series of tests, it was necessary to find the time required for contact between the adsorbent and the solution. Since contact time is a factor that depends on the volume passed through a bed of the adsorbent three different volumes were tested. 1000,500 and $200 \mathrm{ml}$ of the solution at $200 \mathrm{mg}$. liter concentration were passed through the silica sample and it was found that the amount of reagent adsorbed remained constant within $5 \%$. Thus the selected adsorption time was equivalent to the time required to pass $200 \mathrm{ml}$ of test solutions through the bed of a particular sample. Depending on the actual size of this sample it could vary from half an hour to about one hour. It was found 
that the results were satisfactorily reproducible without the application of suction to the system.

\section{The Adsorption Column}

As illustrated in Fig. 1, the adsorption column is a simple experimental apparatus, to determine the adsorption of dehydroabietylamine on the surface of silica and specularite.

A sample was weighed out accurately on an analytical balance and the desired concentration of the solution made up for each test in $500 \mathrm{ml}$ volumes. Two $200 \mathrm{ml}$ volumes of the solution were used for duplicate tests and the remaining $100 \mathrm{ml}$ for analytical determination.

To eliminate the error due to adsorption on the fritted glass filter before each test, approximately $50 \mathrm{ml}$ of the test solution was allowed to pass through the filter, thus bringing it to equilibrium with the solution.

Similarly, after each test the filters were flushed with boiling distilled water.

In the adsorption tests, the sample was placed in the fritted glass filter and well mixed with a small portion of the solution. When thorough wetting was assured, a funnel was attached to the filter with a rubber stopper, maintaining a constant solution coverage over the bed of sample.

After the $200 \mathrm{ml}$ of solution passed through the sample, a weak suction was applied to remove some of the inter stitial liquid. 


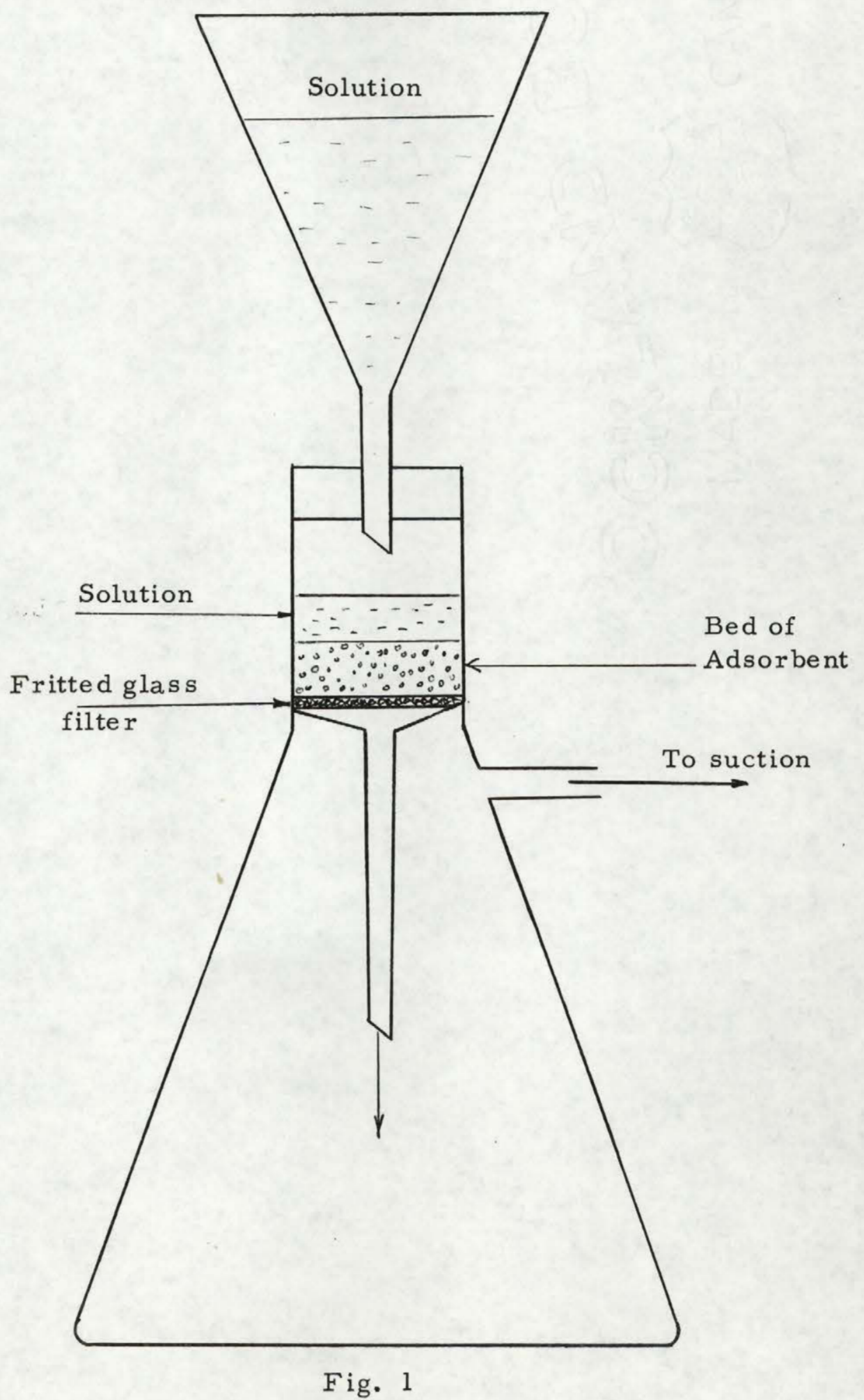


After its passage through the column, the concentration of the solution was determined and the difference between the two determinations, before and after adsorption, was plotted against the concentration of the original solution as a characteristic value of the amount of adsorption.

The main drawback of such spectophotographic determinations was the limited concentration range with a maximum value of $20 \%$ mg/liter. Most solutions, above this value, could only be determined indirectly by diluting them to a suitable range, approximately $10 \mathrm{ppm}$, and then recalculating the actual value for the solution. (Appendix I) 


\section{EXPERIMENTAL RESULTS}

The following six tables contain the data obtained during the investigation.

Tables 1 and 2 contain information regarding the adsorption behaviour of dehydroabietylamine acetate from nearly neutral pH solutions. The $\mathrm{pH}$ varied from 6.3 to 6.9 for a concentration range of $5 \mathrm{mg}$. liter to $1000 \mathrm{mg} /$ liter, the $\mathrm{pH}$ increasing slightly, with the increase in concentration.

All tests were carried out at room temperature with an approximate variation of $5^{\circ} \mathrm{C}$.

The amount of adsorption that takes place at the interface can be expressed as the weight of adsorbate per unit weight of adsorbent. However, a direct comparison between the quartz and hematite would not be possible because of the differences in their specific surface values. Therefore, the adsorption value is expressed as the weight of adsorbate per unit area of the adsorbent surface. The se values are plotted on the graphs, corresponding to the tables, and shown in Fig. 2.

Similar remarks hold for the remaining four tables with the only addition, that in those tests the $\mathrm{pH}$ of the solution was usually adjusted to some value different from the natural $\mathrm{pH}$ values. O. IN $\mathrm{NaOH}$ was used for $\mathrm{pH}$ adjustments.

Tables 5 and 6 contain information on the effect of $\mathrm{pH}$ on adsorption. The concentration of the solution was maintained at approximately $200 \mathrm{mg} / 1$ ite $\mathrm{r}$ and the $\mathrm{pH}$ varied from 6 to 11 . beyond $\mathrm{pH} 11$ precipitation takes place rapidly. 
Calculation of Surface Coverage by Dehydroabietylamine Acetate

Molecular cross sectional area (7), (8)

$50(A)^{2}=5 \times 10^{-15} \mathrm{~cm}^{2}$

Specific surface of silica

$2811 \mathrm{~cm}^{2} / \mathrm{gr}$

Specific surface of hematite

$1689 \mathrm{~cm}^{2} / \mathrm{gr}$

Molecular weight of dehydroabietylamine acetate

$346 \mathrm{gr} / \mathrm{mole}$

No. of molecules in $346 \mathrm{mg}$

$6.02 \times 10^{20}$

No. of molecules in $1 \mathrm{mg}$

$1.7398 \times 10^{18}$

Molecules required to cover $1 \mathrm{gr}$. of $\mathrm{SiO}_{2}$ surface $5.622 \times 10^{17}$

Amount of dehydroabietylamine acetate to cover

$0.3244 \mathrm{mg}$

1 gram of $\mathrm{SiO}_{2}$ surface

Amount of dehydroabietylamine acetate to cover

$1 \mathrm{~cm}^{2}$ surface

$0.11495 \times 10^{-3} \mathrm{mg}$ 
TABLE 1.

ADSORPTION OF DEHYDROABIETYLAMINE ON QUARTZ; $S . S_{.}=2,811 \mathrm{~cm}^{2} / \mathrm{g}$.

\begin{tabular}{|c|c|c|c|c|c|c|c|c|c|c|}
\hline \multirow{2}{*}{$\begin{array}{l}\text { Test } \\
\text { No. }\end{array}$} & \multirow{2}{*}{$\begin{array}{c}\text { Conc'n } \\
\text { Before } \\
\mathrm{mg} / 1\end{array}$} & \multirow{2}{*}{$\begin{array}{c}\text { of } \text { Sol'n }^{\prime} \mathrm{n} \\
\text { After } \\
\text { mg } / 1\end{array}$} & \multirow{2}{*}{$\begin{array}{c}\text { Volume } \\
\text { passed } \\
\mathrm{ml} \\
\end{array}$} & \multirow{2}{*}{$\begin{array}{l}\text { Amount } \\
\text { adsorbed } \\
\text { mg } \\
\end{array}$} & \multirow{2}{*}{$\begin{array}{l}\text { Wt. of } \\
\text { sample } \\
\mathrm{g} \\
\end{array}$} & \multicolumn{2}{|c|}{ Adsorption } & \multirow{2}{*}{$\begin{array}{l}\mathrm{pH} \text { of } \\
\text { sol'n }\end{array}$} & \multirow{2}{*}{$\begin{array}{l}\text { Temp. } \\
{ }^{\circ} \mathrm{C}\end{array}$} & \multirow{2}{*}{$\begin{array}{l}\text { osurface } \\
\text { coverage }\end{array}$} \\
\hline & & & & & & $\begin{array}{l}\mathrm{mg} / \mathrm{g} \\
\mathrm{SiO}_{2}\end{array}$ & $\begin{array}{c}\left(\mathrm{mg} / \mathrm{cm}^{2}\right) \\
\times 10^{-3} \\
\end{array}$ & & & \\
\hline 1 & 5.0 & 4.5 & 200 & 0.0921 & 5.617 & 0.0164 & 0.00583 & 杢 & $H_{0}^{-1}$ & 5.07 \\
\hline 2 & 11.0 & 10.45 & 200 & .116 & 5.288 & 0.022 & .00782 & & 3 & 7.81 \\
\hline 3 & 24.4 & 23.1 & 200 & .270 & 4.980 & .053 & .01885 & 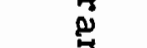 & ? & 16.40 \\
\hline 4 & 36.0 & 34.18 & 200 & .364 & 4.987 & .073 & .02596 & 品 & 4 & 22.59 \\
\hline 5 & 46.7 & 42.8 & 200 & .780 & 6.571 & .119 & .04233 & $\therefore$ & 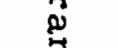 & 35.71 \\
\hline 6 & 54.0 & 48.0 & 200 & 1.20 & 8.282 & .145 & .05158 & & oq & 44.89 \\
\hline 7 & 95.0 & 88.0 & 200 & 1.40 & 6.169 & .227 & .08074 & $\because$ & $\therefore$ & 70.27 \\
\hline 8 & 200.0 & 189.0 & 200 & 2.20 & 7.364 & .299 & .10636 & $\begin{array}{l}\omega \\
+\end{array}$ & $N$ & 92.60 \\
\hline 9 & 269.0 & 251.7 & 200 & 3.45 & 8.261 & .418 & .14870 & 0 & $\omega$ & 129.41 \\
\hline 10 & 368.0 & 341.2 & 200 & 5.36 & 9.402 & .569 & .20241 & $\sigma$ & $\Omega$ & 177.89 \\
\hline 11 & 401.0 & 370.0 & 200 & 6.20 & 8.748 & .708 & .25186 & 0 & & \\
\hline 12 & 430.0 & 380.0 & 200 & 10.00 & 9.270 & 1.08 & .38420 & & 0 & \\
\hline 13 & 484.0 & 465.0 & 200 & 3.8 & 9.125 & .416 & .14799 & & $\underset{\infty}{N}$ & \\
\hline 14 & 540.0 & 495.5 & 200 & 8.9 & 8.187 & 1.09 & . 38776 & & 0 & \\
\hline 15 & 640.0 & 590.0 & 200 & 10.0 & 7.059 & 1.318 & .46887 & & $\Omega$ & \\
\hline 16 & 853.0 & 790.0 & 200 & 12.6 & 7.048 & 1.79 & .63678 & & & \\
\hline 17 & 1075.0 & 875.0 & 200 & 40.0 & 7.431 & 5.72 & 2.03486 & & & \\
\hline
\end{tabular}


TABLE 2 .

ADSORPTION OF DEHYDROABIETYLAMINE ACETATE ON HEMATITE;

S.S. $=1,689 \mathrm{~cm}^{2} / \mathrm{g}$

\begin{tabular}{|c|c|c|c|c|c|c|c|c|}
\hline \multirow{2}{*}{$\begin{array}{l}\text { Test } \\
\text { No. }\end{array}$} & \multirow{2}{*}{$\begin{array}{c}\frac{\text { Conc'n }}{\text { Before }} \\
\mathrm{mg} / 1\end{array}$} & \multirow{2}{*}{$\begin{array}{l}\text { of } \text { Sol'n }^{\prime} \mathrm{n} \\
\text { After } \\
\mathrm{mg} / 1 \\
\end{array}$} & \multirow{2}{*}{$\begin{array}{c}\text { Volume } \\
\text { passed } \\
\mathrm{ml} \\
\end{array}$} & \multirow{2}{*}{$\begin{array}{c}\text { Amount } \\
\text { adsorbed } \\
\text { mg }\end{array}$} & \multirow{2}{*}{$\begin{array}{l}\text { Wt. of } \\
\text { sample } \\
\mathrm{g} \\
\end{array}$} & \multicolumn{2}{|c|}{ Adsorption } & \multirow{2}{*}{$\begin{array}{l}\text { osurface } \\
\text { coverage }\end{array}$} \\
\hline & & & & & & $\begin{array}{l}\mathrm{mg} / \mathrm{g} \\
\mathrm{SiO}\end{array}$ & $\begin{array}{c}\left(\mathrm{mg} / \mathrm{cm}^{2}\right) \\
\mathrm{x} 10^{-3}\end{array}$ & \\
\hline 1 & 16.8 & 16.1 & 200 & 0.14 & 9.541 & 0.014 & 0.0082 & 7.13 \\
\hline 2 & 67.5 & 63.5 & 200 & .80 & 8.684 & .092 & .0544 & 47.34 \\
\hline 3 & 102.0 & 92.0 & 200 & 2.00 & 11.192 & .178 & .1053 & 91.64 \\
\hline 5 & 93.0 & 82.0 & 200 & 2.20 & 11.841 & .185 & .1098 & \\
\hline 6 & 306.0 & 281.0 & 200 & 5.00 & 11.548 & .351 & .2078 & \\
\hline 7 & 430.0 & 410.0 & 200 & 4.00 & 11.823 & .340 & .2013 & \\
\hline 8 & 748.0 & 708.0 & 200 & 6.80 & 13.959 & .487 & .2883 & \\
\hline 9 & 587.0 & 560.0 & 200 & 5.40 & 13.927 & .388 & .2297 & \\
\hline
\end{tabular}

pH range: 6.3 to 6.9

Temp, range: $23^{\circ} \mathrm{C}$ to $28^{\circ} \mathrm{C}$ 
TABLE 3 .

ADSORPTION ON QUARTZ IN BASIC SOLUTIONS.

\begin{tabular}{|c|c|c|c|c|c|c|c|c|c|}
\hline \multirow{2}{*}{$\begin{array}{l}\text { Test } \\
\text { No. }\end{array}$} & \multirow{2}{*}{$\begin{array}{c}\text { Conc'n } \\
\text { Before } \\
\mathrm{mg} / 1 \\
\end{array}$} & \multirow{2}{*}{$\begin{array}{l}\text { Sol'n }^{\prime} \text { After } \\
\text { mg } / 1\end{array}$} & \multirow{2}{*}{$\begin{array}{c}\text { Volume } \\
\text { passed } \\
\mathrm{ml} \\
\end{array}$} & \multirow{2}{*}{$\begin{array}{l}\text { Amount } \\
\text { adsorbed } \\
\text { mg }\end{array}$} & \multirow{2}{*}{$\begin{array}{l}\text { Wt. of } \\
\text { sample } \\
\mathrm{g} \\
\end{array}$} & \multicolumn{2}{|c|}{ Adsorption } & \multirow[b]{2}{*}{$\mathrm{pH}$} & \multirow[b]{2}{*}{ REMARKS } \\
\hline & & & & & & $\begin{array}{l}\mathrm{mg} / \mathrm{g} \\
\mathrm{SiO}_{2}\end{array}$ & $\begin{array}{c}\left(\mathrm{mg} / \mathrm{cm}^{2}\right) \\
\times 10^{-3} \\
\end{array}$ & & \\
\hline 1 & 20.0 & 4.0 & 200 & 3.2 & 5.205 & 0.730 & 0.2597 & 10.2 & \\
\hline 2 & 45.7 & 5.5 & 200 & 8.03 & 5.253 & 1.514 & .5386 & 9.9 & 1eilperalure \\
\hline 3 & 95.0 & 0.0 & 200 & 19.0 & 4.586 & 4.14 & 1.4728 & 10.0 & test series. \\
\hline 4 & 207.0 & 93.0 & 200 & 23.1 & 5.652 & 4.07 & 1.4479 & 8.8 & est series: \\
\hline 5 & 283.0 & 36.0 & 200 & 49.4 & 5.494 & 8.90 & 3.1661 & 10.0 & $23^{\circ} \mathrm{C}$ \\
\hline 6 & 380.0 & 33.0 & 200 & 69.4 & 7.101 & 9.80 & 3.4863 & 9.9 & 200 \\
\hline 7 & 510.0 & 165.0 & 200 & 69.0 & 4.917 & 14.37 & 5.1136 & 10.0 & \\
\hline 8 & 730.0 & 234.0 & 200 & 99.2 & 5.083 & 19.15 & 6.8120 & 9.0 & \\
\hline
\end{tabular}


TABLE 4.

ADSORPTION ON HEMATITE IN BASIC SOLUTIONS.

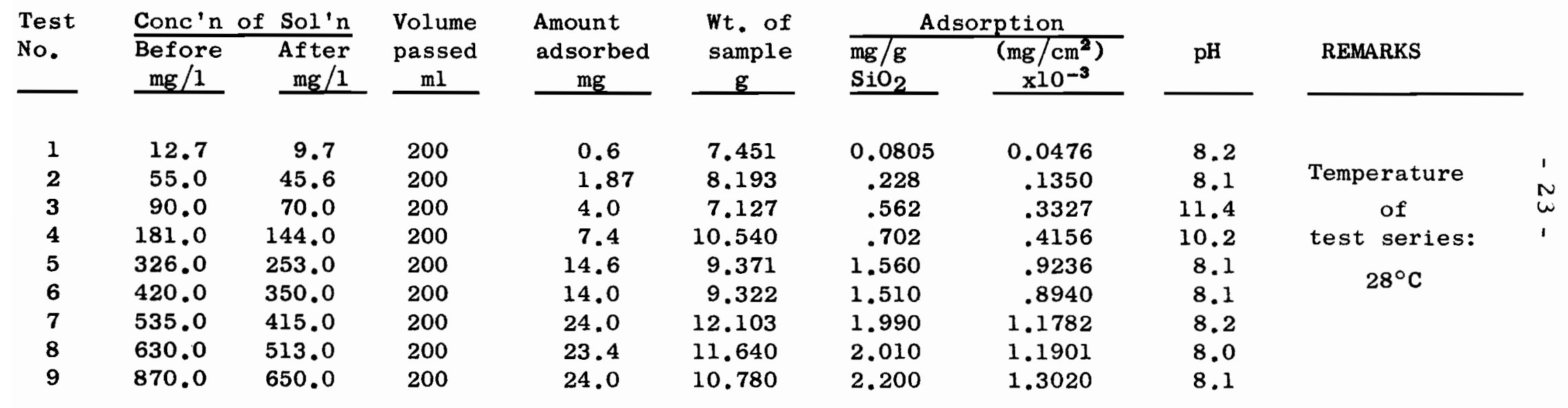


TABLE 5 .

ADSORPTION ON HEMATITE WITH CHANGING $\mathrm{pH}$.

Concentration: $205 \mathrm{mg} / \mathrm{l}$

\begin{tabular}{|c|c|c|c|c|c|c|c|c|}
\hline \multirow{3}{*}{$\begin{array}{l}\text { Test } \\
\text { No. }\end{array}$} & \multirow{2}{*}{\multicolumn{2}{|c|}{$\begin{array}{c}\text { Acetate in } 200 \mathrm{ml} \\
\text { solution }\end{array}$}} & \multirow{3}{*}{$\begin{array}{l}\text { Amount } \\
\text { adsorbed } \\
\text { mg } \\
\end{array}$} & \multirow{3}{*}{$\begin{array}{l}\text { Wt. of } \\
\text { sample } \\
\mathrm{g} \\
\end{array}$} & \multicolumn{2}{|c|}{ Adsorption } & \multirow[t]{3}{*}{$\mathrm{pH}$} & \multirow[t]{3}{*}{ REMARKS } \\
\hline & & & & & \multirow{2}{*}{$\begin{array}{l}\mathrm{mg} / \mathrm{g} \\
\mathrm{SiO}\end{array}$} & \multirow{2}{*}{$\begin{array}{c}\left(\mathrm{mg} / \mathrm{cm}^{2}\right) \\
\times 10^{-3} \\
\end{array}$} & & \\
\hline & Before & After & & & & & & \\
\hline & $\mathrm{mg}$ & $\mathrm{mg}$ & & & & & & \\
\hline 1 & 41.0 & 39.2 & 1.8 & 10.187 & 0.177 & 0.1048 & 6.3 & \\
\hline 2 & 41.0 & 6.8 & 34.2 & 12.226 & 2.790 & 1.6518 & 10.4 & \\
\hline 3 & 41.0 & 18.4 & 22.6 & 9.674 & 2.330 & 1.3795 & 8.0 & Temperature \\
\hline 4 & 41.0 & 11.4 & 29.6 & 11.688 & 2.530 & 1.4979 & 9.1 & of \\
\hline 5 & 41.0 & 6.1 & 34.9 & 13.125 & 2.590 & 1.5334 & 10.1 & test series: \\
\hline 6 & 41.0 & 0.7 & 40.3 & 13.684 & 2.950 & 1.7466 & 11.1 & \\
\hline 7 & 41.0 & 39.0 & 2.0 & 12.535 & 0.160 & 0.0947 & 7.3 & $24^{\circ} \mathrm{C}$ \\
\hline 8 & 41.0 & 39.5 & 1.47 & 8,791 & 0.168 & 0.0994 & 6.7 & \\
\hline 9 & 41.0 & 32.9 & 8.1 & 9.734 & 0.850 & 0.5032 & 7.7 & \\
\hline 10 & 38.0 & 3.0 & 35.0 & 10.736 & 2.750 & 1.6282 & 9.8 & \\
\hline
\end{tabular}


TABLE 6 .

ADSORPTION ON SILICA WITH CHANGING $\mathrm{pH}$.

Concentration: $205 \mathrm{mg} / 1$

\begin{tabular}{|c|c|c|c|c|c|c|c|c|}
\hline \multirow[t]{2}{*}{$\begin{array}{l}\text { Test } \\
\text { No. }\end{array}$} & \multicolumn{2}{|c|}{$\begin{array}{l}\text { Acetate in } 200 \mathrm{ml} \\
\text { solution }\end{array}$} & \multirow{2}{*}{$\begin{array}{l}\text { Amount } \\
\text { ad sorbed } \\
\text { mg } \\
\end{array}$} & \multirow{2}{*}{$\begin{array}{l}\text { Wt. of } \\
\text { sample } \\
\mathrm{g} \\
\end{array}$} & \multicolumn{2}{|c|}{ Adsorption } & \multirow[t]{2}{*}{$\mathrm{pH}$} & \multirow[t]{2}{*}{ REMARKS } \\
\hline & Before & After & & & $\mathrm{SiO}_{2}$ & $\times 10^{-3}$ & & \\
\hline & & & & & & & & \\
\hline 1 & 41.0 & 38.8 & 2.2 & 7.364 & 0.299 & 0.1063 & 6.7 & \\
\hline 2 & 41.0 & 1.5 & 39.5 & 6.992 & 5.660 & 2.0130 & 10.3 & \\
\hline 3 & 41.0 & 26.4 & 14.6 & 6.684 & 2.190 & 0.7791 & 8.4 & Temperature \\
\hline 4 & 41.0 & 34.4 & 6.6 & 5.461 & 1.210 & 0.4305 & 8.3 & \\
\hline 5 & 41.0 & 36.4 & 4.6 & 5.087 & 0.910 & 0.3237 & 8.2 & of \\
\hline 6 & 41.0 & 38.8 & 2.2 & 6.484 & 0.340 & 0.1209 & 7.4 & test series: \\
\hline 7 & 41.0 & 19.9 & 21.1 & 5.179 & 4.070 & 1.4478 & 8.8 & \\
\hline 8 & 38.0 & 2.8 & 35.2 & 6.144 & 5.720 & 2.0348 & 9.8 & $24^{\circ} \mathrm{C}$ \\
\hline
\end{tabular}


The possible reversibility of the process was investigated by desorbing from the point obtained with the highe st concentration of the solution. In the first two stages strong suction was applied to the system. Equilibrium conditions prevailed during the last two stages of the desorption process. The following table summarizes the results of the desorption tests.

There are two assumptions made in connection with the results of the desorption tests. The first one is that the solution remaining In the bed of adsorbent above the fritted glass filter has the same concentration as the effluent and the second one is that if this concentration is greater than that of the effluent, then the volume of the residual solution is comparatively small and its effect on the total $200 \mathrm{ml}$ solution is still negligible.

To maintain a constant volume circulating in the desorption tests, only a $50 \mathrm{ml}$ volume of the effluent was removed for determinations and replaced by $50 \mathrm{ml}$ of wate $\mathrm{r}$ to dilute its concentration. The solution, made up of $(150-x) \mathrm{ml}$ then returned for the next desorption test. $\mathbf{x}$ is the volume of solution retained in the bed and its volume is estimated to be between 2 to $4 \mathrm{ml}$.

Although the accuracy of determination diminishes rapidly at very low concentrations, it nevertheless appears from Fig. 2 that the adsorption of dehydroabietylamine acetate is of the physical nature. 
TABLE 7 .

ADSORPTION DATA ON QUARTZ IN NEAR NEUTRAL SOLUTIONS.

\begin{tabular}{|c|c|c|c|c|}
\hline $\begin{array}{l}\text { Test } \\
\text { No. }\end{array}$ & $\begin{array}{l}\text { Initial } \\
\text { Conc'n } \\
\mathrm{mg} / 1 \\
\end{array}$ & $\begin{array}{c}\text { Volume } \\
\text { passed } \\
m 1\end{array}$ & $\begin{array}{l}\text { Amount } \\
\text { adsorbed } \\
\mathrm{mg} / \mathrm{g} \mathrm{SiO} 2\end{array}$ & $\begin{array}{l}\text { Wt. of } \\
\text { sample } \\
\mathrm{g}\end{array}$ \\
\hline 1 & 655 & 200 & 0.404 & 7.431 \\
\hline 2 & 630 & 200 & 0.080 & 7.431 \\
\hline 3 & 480 & 200 & 1.076 & 7.431 \\
\hline 4 & 215 & 200 & 0.471 & 7.431 \\
\hline
\end{tabular}

\begin{tabular}{l} 
REMARKS \\
\hline Solution passed with strong suction \\
Solution passed with strong suction \\
Solution passed without suction \\
Solution passed without suction \\
Temperature of tests: $24^{\circ} \mathrm{C}$ \\
pH range: 6.3 to 6.6
\end{tabular}

Data from this table are plotted in Fig. 2. 


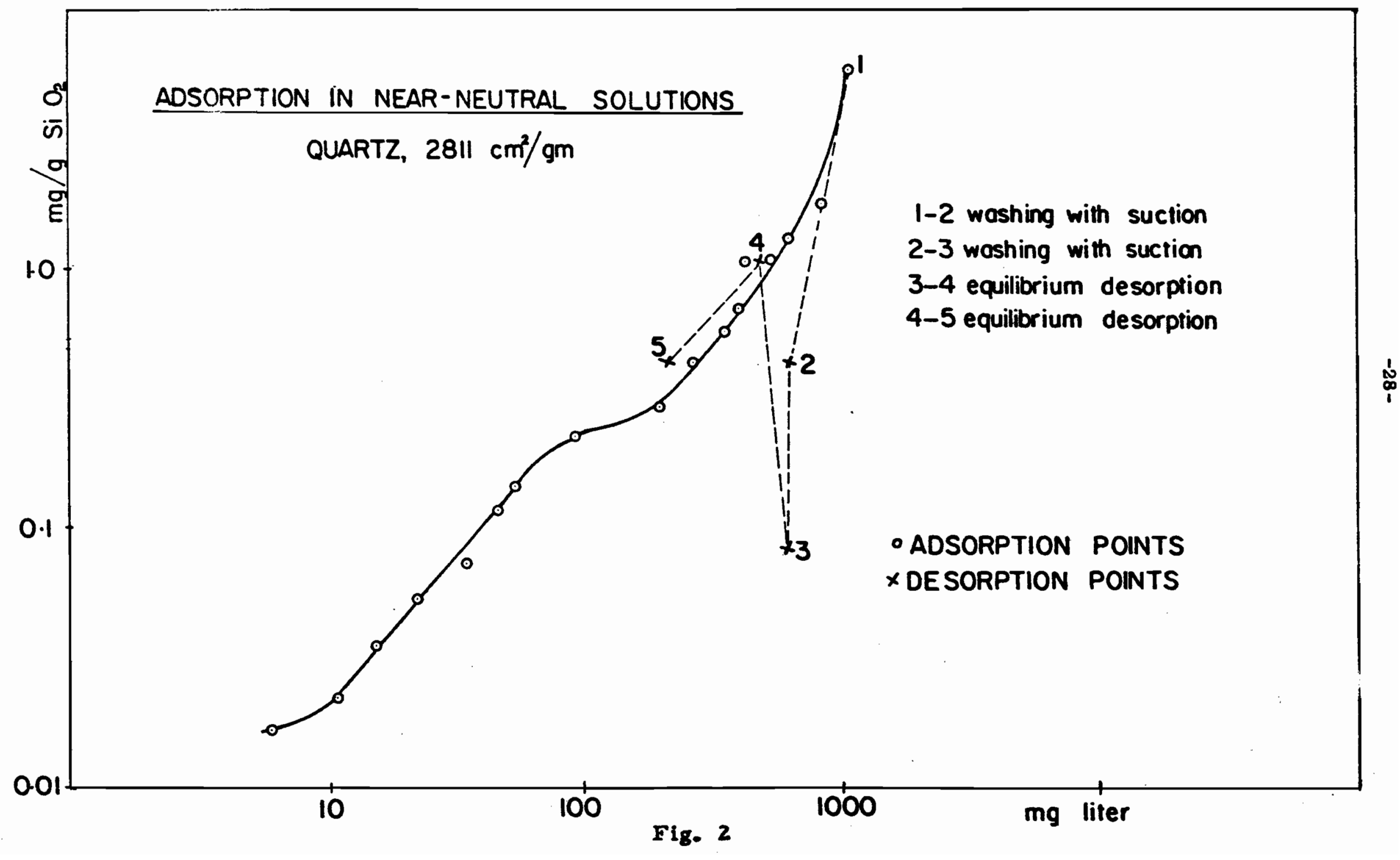




\section{DISCUSSION OF RESULTS}

The purpose of this investigation was to establish the adsorption characteristics of a cationic collector of a more complete truturethan the straight hydrocarbon chains. Aqueous solutions of dehydroabietylamine acetate were used and it is as sumed that the ionized dehydroabietylamine takes part in the adsorption. Terminology referring to the adsorption of dehydroabietylamine is only a matter of conveniencesince evidence is not available as to the actual participation of the acetate radical in the surface phenomenon.

These tests were designed to yield information regarding the adsorption behaviour of dehydroabietylamine on quartz and specular hematite and the dependence of adsorption on concentration and $\mathrm{pH}$ of the solution.

Adsorption in Near Neutral Solutions

Adsorption and desorption results with quartz in near neutral solution are plotted on Fig. 2, $\log -\log$ scales are used to accommodate the wide range of concentrations tested and the amounts adsorbed. From the curve it becomes obvious that at lower concentrations the relationship is linear. The slope of this linear section is approximately $45^{\circ}$.

The first noticeable change in direction occurs between the points cobtained at 100 and $200 \mathrm{mg} / \mathrm{liter}$ concentration. This is rather significant because it serves as a confirmation of the empirical findings that the adsorption rate changes at the point where a monolayer is completed. The intersection of the calculated line of monolayer coverage 
intersects the isotherm at the $200 \mathrm{mg} /$ liter concentration.

Two such "breaks" in the direction of the isotherm

exist - one at $200 \mathrm{mg} / 1$ iter and the other at about $500 \mathrm{mg} / \mathrm{lite}$.

Because of possible micell formation concentrations above

$1000 \mathrm{mg} /$ liter were not tested.

There exists a remarkable similarity between these adsorption results and the results of other investigators (4) with straight chain collectors. The rate of adsorption is somewhat higher but the general trend of the variation versus concentration is very similar.

It is questionable whether, based on one isotherm, one can assign a mathematical relationship to express the adsorption characteristics of any one particular system. The writer feels that more extensive research is required before a tested relationship can be established.

The calculated surface coverage on the quantz at the lowest concentration tested is $5.10 \%$ and at $200 \mathrm{mg} / \mathrm{liter}$ this coverage is $92.6 \%$ which is almost one complete monolayer. At the highest tested concentration the surface coverage is several layers thick. Very little is known about the actual disposition or the structure of these layers adsorbed on the solld surfaces.

Gaudin and Fuerstenau((17) - investigated the mechanism of the flotation of quartz by cationic collectors. They found that the se collectors change the sign of the electrokinetic potential at a given concentration. According to these investigators the decrease in electrokinetic potential 
is evidence that the adsorbed layer changes its structure by forming what they call "hemi-mlcellg". Adsorption calculations indicate that collectors form multilayer coatlnge on the surfaces of minerals. However, such calculations are always inekact because the re is no evidence that the coverage is uniform on the surface. Despite this Inaccuracy involved in the calculations it is assured that it can only give the lower limit of the resulting multilayer adsorption (2). As a rule, it is considered that the adrorption is unlformiy distributed over the surface.

Desorption in Near Neutral Solutions

According to the definltion of physical adsorption: the process is pontaneous and reversible. So far it was found that the process was spontaneous but the latter part remalned to be investigated. It is a very common statement one finds in recent texts on flotation that "catlonic collectors adsorb reverslbly on minerals, lowering the hydratin of thels surfaces" (2).

Results of tests to check the reversibllity of adsorption with dehydroabletylamlne acetate are plotted in Fig. 2 with the adsorptlon data and the polnts are numbered from 1 to 5 .

Durlng the first two stage vuction wa applied to the system to find out the effect of mechanleal conditions. In the second otage the solution concentration was about the same as the effluent of the first stage, yet the desorption value reached a low of $0.08 \mathrm{mg} / \mathrm{gr} \mathrm{SiO}_{2}$, 
clearly indicating that the force of washing was to account for the de sorption.

In the last two stages: $(3-4),(4-5)$, the solution was allowed to pass the bed of silica without applying suction to the system and consequently the values reached the same magnitude as obtained with the previous adsorption tests.

With most of the monolayer coverage of the surface removed it now appears this is also a certain case of physical adsorption. Definite features of the adsorption desorption curves show that the properties defining the phenomenon are present and available for identification.

The actual mechanism of collector adsorption on mineral surfaces is still in a hypothetical state. There is har dly a unique explanation possible, but the most reasonable assumption is that it is composed of various mechanisms commencing at various phases of the adsorption process. For the first phase of the process the electrical double layer phenomenon may be used as a fundamental mechanism describing the cause and the manner in which large heteropolar compounds could be a.dsorbed.

Solid surfaces do not remain inert when they are submerged in liquids. The reaction between the water and the ions it carries changes the composition and the electrical character of the mineral surface. A characteristic feature of the reactions between the components of the liquid phase and the solid surface is that they are not uniform in energy. 
This means that the rate at which one kind of ion leaves the solid surface and enters the solution is greater than this rate for another ion. Consequently the electrical neutrality of the solid surface is impaired. The first result of this rate difference is the formation of a charged surface opposite in charge to the charge of the ions with the highest rate of dissolution.

When an equilibrium state is achieved between the solid surface and the solution, the solid surface will be surrounded by a double electric layer. The structure of such a double layer can be illustrated by a simplified diagram (11).

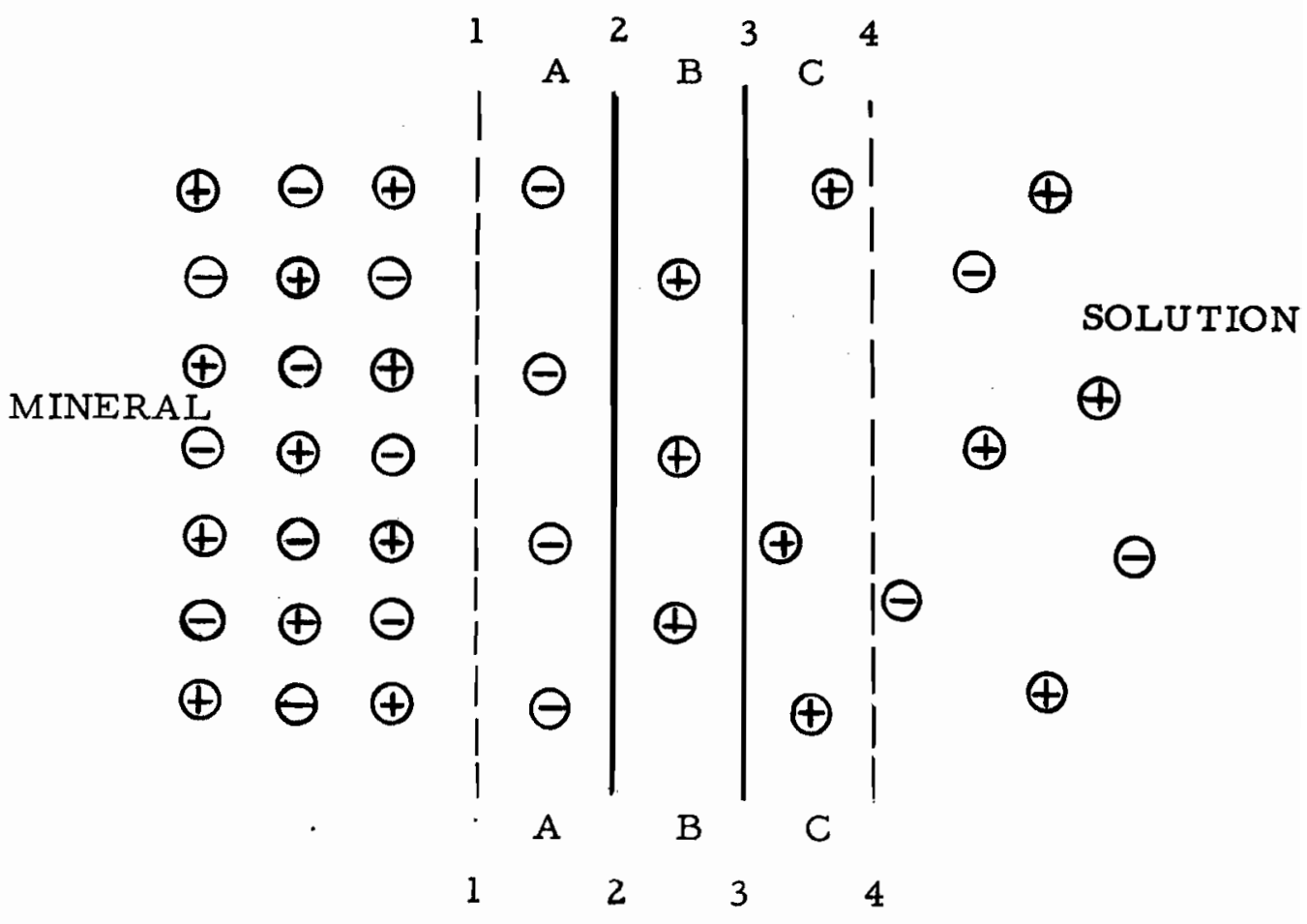

Fig. 3.

The structure of the electric double layer formed on a mineral surface in aqueous solutions 
1-1 Boundary between unaltered crystal lattice and charged surface layer.

A-A. Inner: part of the double layer

2-2 Actual physical boundary between the solid and the liquid phases.

B-B Outer part of the double layer with regularly ar ranged cations.

3-3 Boundary between ordered part of outer skin and diffused part.

C-C Diffused layer of the outer skin.

4-4 Boundary between the outer skin of the diffused layer and the solution.

The inner skin of the double layer is firmly attached to the mineral surface and naturally move with the solid particles. The cations in the outer layers only represent a part of the total number of cations that left the mine ral surface. The diffused layer, beyond the 3-3 line contains the balance of these cations. As the distance increases from the 3-3 line the ionic concentration of these cations also decreases. So far the sytem is in electrical equilibrium.

When the particle begins to move in the liquid a lag developss in the diffused layer. As a result a potential difference is set up between the layers A-A and B-B. This potential is a. product of relative movement and is called the zeta potential.

In addition to the zeta potential concept, there is the concept of the thermodynamic or full potential.

The full potential is described as the potential difference between the total ions in the outer skins, to the right of the 2-2 line and the ions to the left of the 2-2 line. Calculation of both potentials reveals that 
the zeta potential is always less than the thermodynamic or the full potential (11). The difference between the two potentials is that they arise at different places in the system: the thermodyamic potential arises at the solid-liquid interface, whereas the electrokinetic potential arises on the slip surface between the fixed and the diffused outer layers.

Ions in solution can react with the outer skin of the electrical double layer or with its inner skin. For example the ionic dimension will determine whether the ion will be adsorbed by the outer skin or in the inner skin. Ions which already exist in the crystal lattice or can easily replace the se will be most readily adsorbed in the double layer's inner skin. Ionic dimensions are the most impbiritanit criteria in this type of adsorption. Such ions that can penetrate into the inner double layer are called potential determining ions.

To support the supposition that dehydroabietylamine acetate adsorbed physically can now be supported by the behaviour of ions of larger size than the ions of the crystal lattice (2). These ions due to their size cannot penetrate into the inner layer and can only be adsorbed in the outer layers of quartz and hematite.

The higher the concentration of the ions of the same size as the ions of the outer skin of the double layer, the greater the proportion of these ions that will pass from the diffused layer into the outer skin. This transfer of ions of the same sign from the solution and the diffused layer into the outer skin of the diffused layer will reduce the zeta 
potential. There exists an electrolyte concentration in the solution at which this transition of ions into the outer skin may practically be complete, reducing the zeta potential to zero. When this is achieved the system becomes isoelectric.

Gaudin and Fuerstenaw illustrate the process of acquiring a surface charge for silica in aqueous solutions (17). They conclude that even in pure water $\mathrm{SiO}_{2}$ has a negatively charged surface and that hydroxyl and hydrogen ions appear to function as potential determining ions in water.

DeBruyn and Parks (16) in a more recent paper express the process of achieving a charge or the formation of the double layer at any oxide surface as:

$$
\mathrm{O}^{-} \text {(surface) }+\mathrm{H}_{\mathrm{z}}, 0=2 \mathrm{OH}^{-} \text {(solution) }
$$

This equation is in agreement with the potential determining role of the $\mathrm{OH}^{-}$and $\mathrm{H}+$ ions. Most investigators (17 to 22) of the properties of the oxide-aqueous solution interface support that the mechanism by which the surface charges established may be viewed as a two-step process; surface hydration followed by dissociation of the surface hydroxyl.

The hydration step may be visualized as an attempt by the exposed surface atoms to complete their cbördination shell of nearest neighbours. Exposed cations accomplish this by pulling an $\mathrm{OH}^{-}$ion or water molecule and the oxygen ions by pulling a proton from the aqueous phase. The net result is that the surface is now covered by a hydroxyl layer with the cations buried below the surface. 
Comparison of Adsorption with quartz and Specular Hematite in Near-neutral Solutions

Adsorption tests, similar to those described in conjunction with Fig. 2 were carried out with pure specular hematite that ranged in size from 270 mesh to 400 mesh. The plot of the results obtained is shown on Fig. 4. with the $\mathrm{pH}$ values ranging between 6.4 and 6.9 The conclusion which can be deduced from the curves is that the behaviour of the two minerals is very similar up to the point of intersection. This point is well above the calculated monolayer coverage. At nearly $200 \mathrm{mg} / \mathrm{liter}$ concentrations the adsøoppion isothe $\mathrm{rm}$ for the hematite changes direction abruptly and almost becomes parallel to the horizontal axis. The point of intersection between the hematite and quartz is at approximately $300 \mathrm{mg} / \mathrm{liter}$ solution concentration. As it was stated before, investigators (15), (16), (17) agree on the process by which an oxide surface becomes changed. They also agree that for practical purposes both the $\mathrm{SiO}_{2}$ and $\mathrm{Fe}_{2} \mathrm{O}_{3}$ surfaces are similar provided the $\mathrm{pH}$ range is suitable. The development of the surface charge occurs in two stepscs:

(i) formation of a surface hydroxide layer due to surface hydration, and

(ii) the dissociation of this hydroxide layer to yield a positively or negatively charged surface, depending on the $\mathrm{pH}$ of the solution.

The latter part deserves more attention, because it provides the key to the understanding for the unusual similarity of these two oxides. 


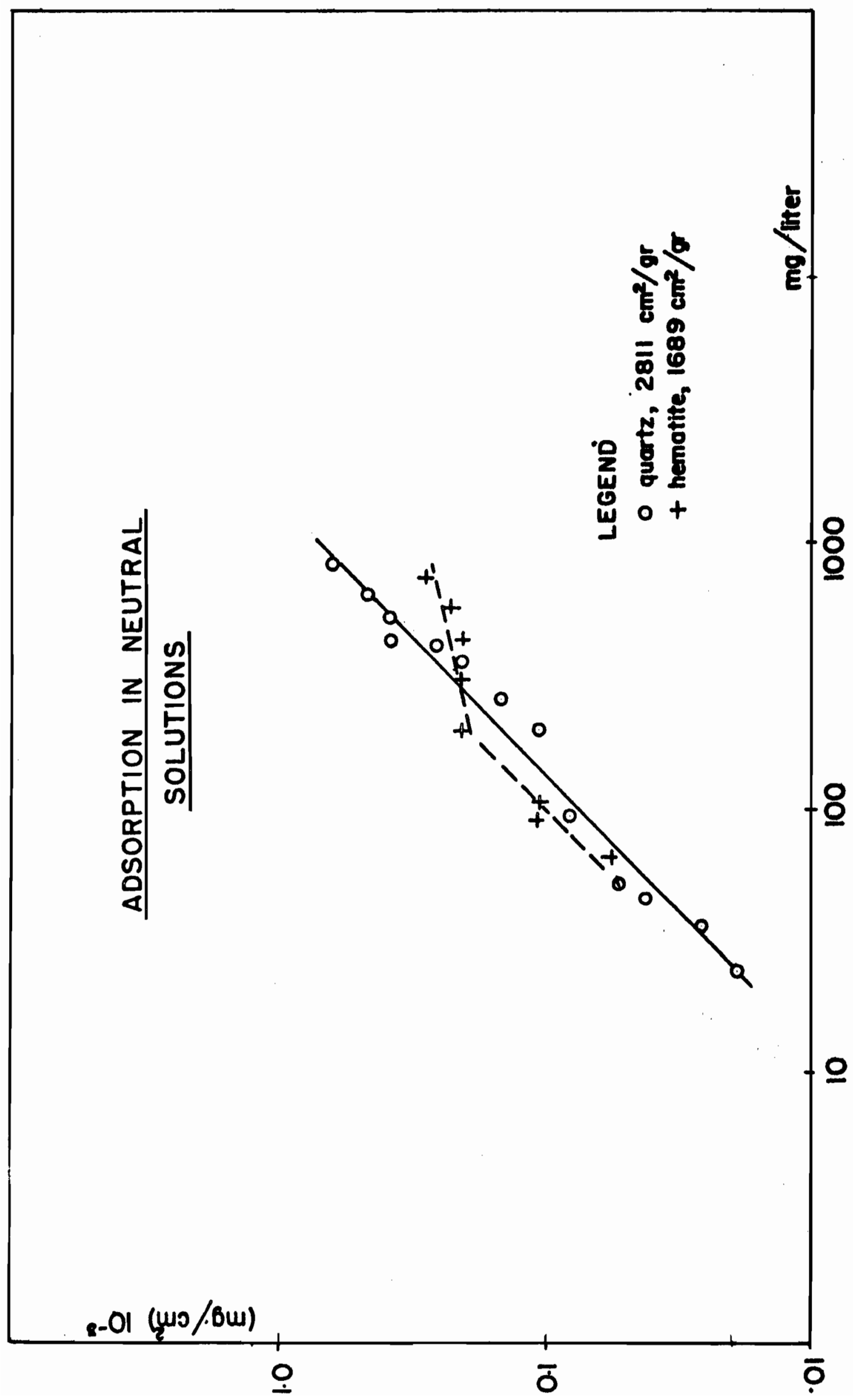


Iwasaki and others (1), (14) found by experiment that the zero point of charge of hematite, goethite and magnetite lies in $\mathrm{pH}$ range of 6.7 to 7.0. Below this $\mathrm{pH}$ the surface of the se ion oxides is positive and above it it is negative. Silica on the other hand can be negatively charged at $\mathrm{pH}$ values as low as $3.0(15)$. Considering now that the $\mathrm{pH}$ range of the present investigations is about 7 or the range similar to the zero point of charge of the ixun oxicles and assuming that both of the surfaces we re negatively charged, the similarity can be explained conveniently.

Joy and Watson (23) found in their experiments that in the case of hematite, the number of collector ions - charged species - correlates with the number of negative sites on the surface. However, the total amount of amine adsorbed was greater than that can be accounted for by ionic adsorption alone, particularly at $\mathrm{pH}$ values far removed from the zero point of charge.

In their work with Itabira specular hematite they found that only at low amine concentrations and high $\mathrm{pH}$ values does the adsorption of charged species account for all the amine adsorption. The amount of adsorption above this region is too great and cannot be accounted for by attachment of collector ions of the type $\mathrm{RNH}_{3}{ }^{+}$. Therefore, another mechanism of adsorptioniis recommended such as attachment of $\mathrm{RNH}_{2}$ through hydrogen bonding.

More quantitative information on the mechanism is lacking at the moment. The available literature provides only assumptions and hypotheses on this subject. 
Comparison of Adsorption Properties of Silica and Hematite at Basic Solutions

The results of Fig. 4 clearly indicated that at $\mathrm{pH} 7$ the adeorption characteristics of the two minerals are too similar to allow effective separation by cationic collection. Consequently, the next step in the investigation was to consider their behaviour at other $\mathrm{pH}$ values further removed from the zero point of charge of he matite.

In the case of quartz the $\mathrm{pH}$ of the solution was maintained constant with one exception where the $\mathrm{pH}$ went to 8 at $207 \mathrm{mg} / \mathrm{liter}$ concentration. The corresponding adsorption value is $1.4479 \mathrm{mg} / \mathrm{Cm}^{2}$ $\times 10^{-3}$ and the adsorption value at $\mathrm{pH}_{10}$ and $95 \mathrm{mg} / \mathrm{lite}$ concentration is $1.4728 \mathrm{mg} / \mathrm{Cm}^{2} \times 10^{-3}$. This undoubtedly leads to the conculusion that a definite driving force exists in the mechanism of adsorption, due to $\mathrm{pH}$, and it has a more profound effect than concentration on the adsorption. (Table 3)

The hematite was tested at $\mathrm{pH}$ of 8 while two tests were run at $\mathrm{pH} 11$ and 10. These two tests have rematmedl close to the isotherms found for $\mathrm{pH}$ 8. Fig. 5 .

An overall look at the curves reveals that there is a very definite shift in the isotherms of both minerals from the position found in Fig. 4. This shift is nearly twice as much for $\mathrm{SiO}_{2}$ as it is for $\mathrm{Fe}_{2} \mathrm{O}_{3}$ and suggests that the silica surface is more sensitive to $\mathrm{pH}$ changes than hematite is .

Fig. 6 throws more light on this problem. In the tests plotted on Fig. 6 the $\mathrm{pH}$ dependence of adsorption was investigated and 


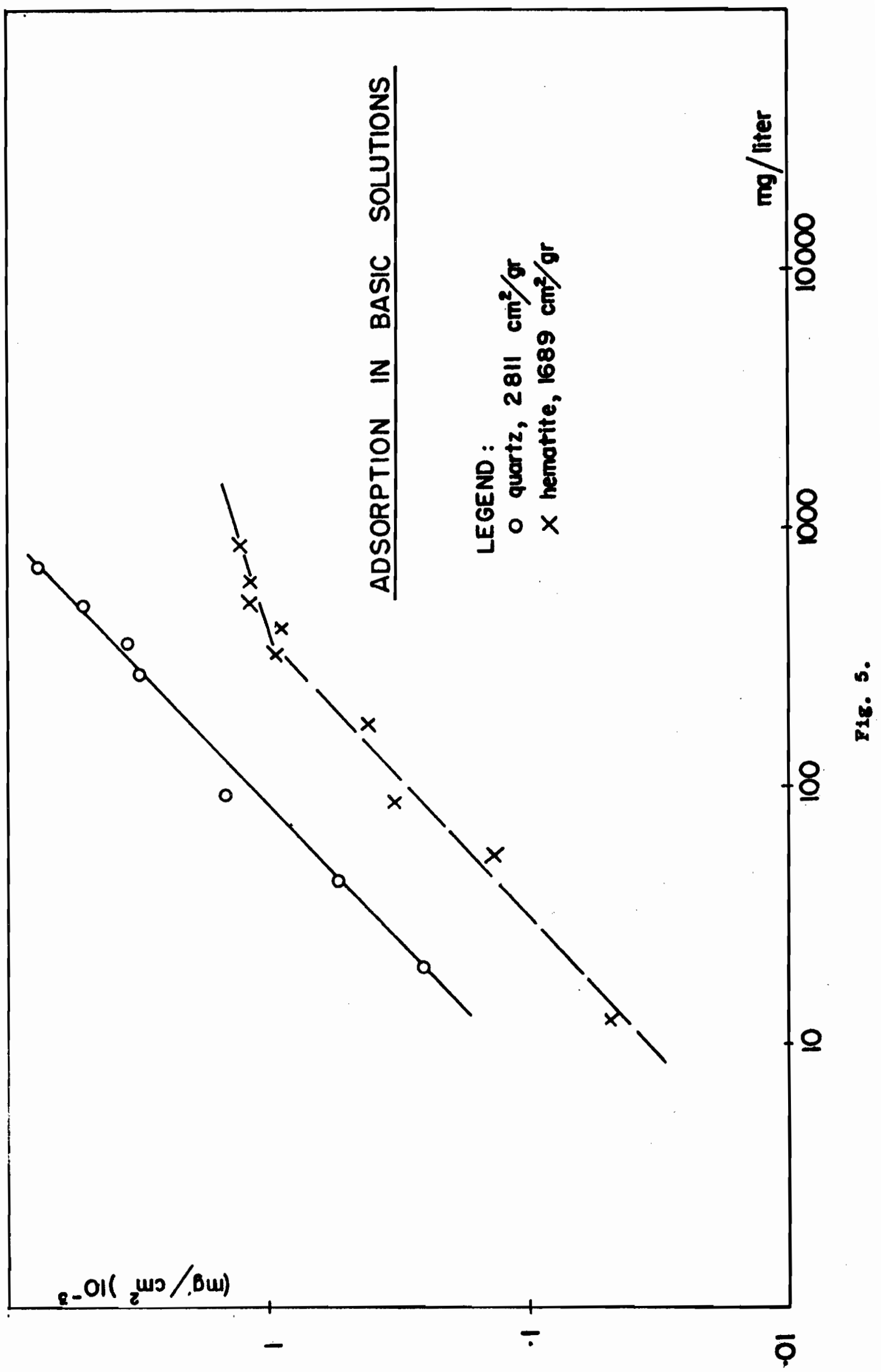


it was found that the critical $\mathrm{pH}$ xange for quartz lies between the values of 8 and 10 while the corresponding range for hematite is found between 7,5 and 8,5 . Above 8.5 the amount adsorbed by hematite remains reasonably constant.

Therefore, the isotherms of Fig. 5 (quartz $\mathrm{pH} \mathrm{10)}$ (hematite $\mathrm{pH} 8$ ) indicate maximum adsorption conditions for both minerals. This explains why the test with silica at pH 8 fell considerably below the line and whey the two tests with hematite at pH 11 and 10 remained so close to their respective isotherm.

Another point worth noting concerning these isotherms is the reoccurrance of the sharp break in the slope of the hematite curve. Superimposing Fig. 3 and Fig. 4, one can observe that the shift of this break is up and to the right. Unfortunately, no explanation of this break is available.

Effect of $\mathrm{pH}$ on the Amount Adsorbed at Constant Concentration

Any investigation of this nature would have been incomplete without establishing the relationship between adsorption and pH while keeping the concentration constant. A series of tests was carried out for silica and hematite at constant solution concentration of $205 \mathrm{mg} / \mathrm{lite}$.

Natural dehydroabietylamine acetate solution was used as a starting point and the pH adjusted with NaOH. The upper limit of the test range was pH 11 , to avoid precipitation of the collector.

The data obtained is presented in Tables 5, 6 and in Fig. 6 . 


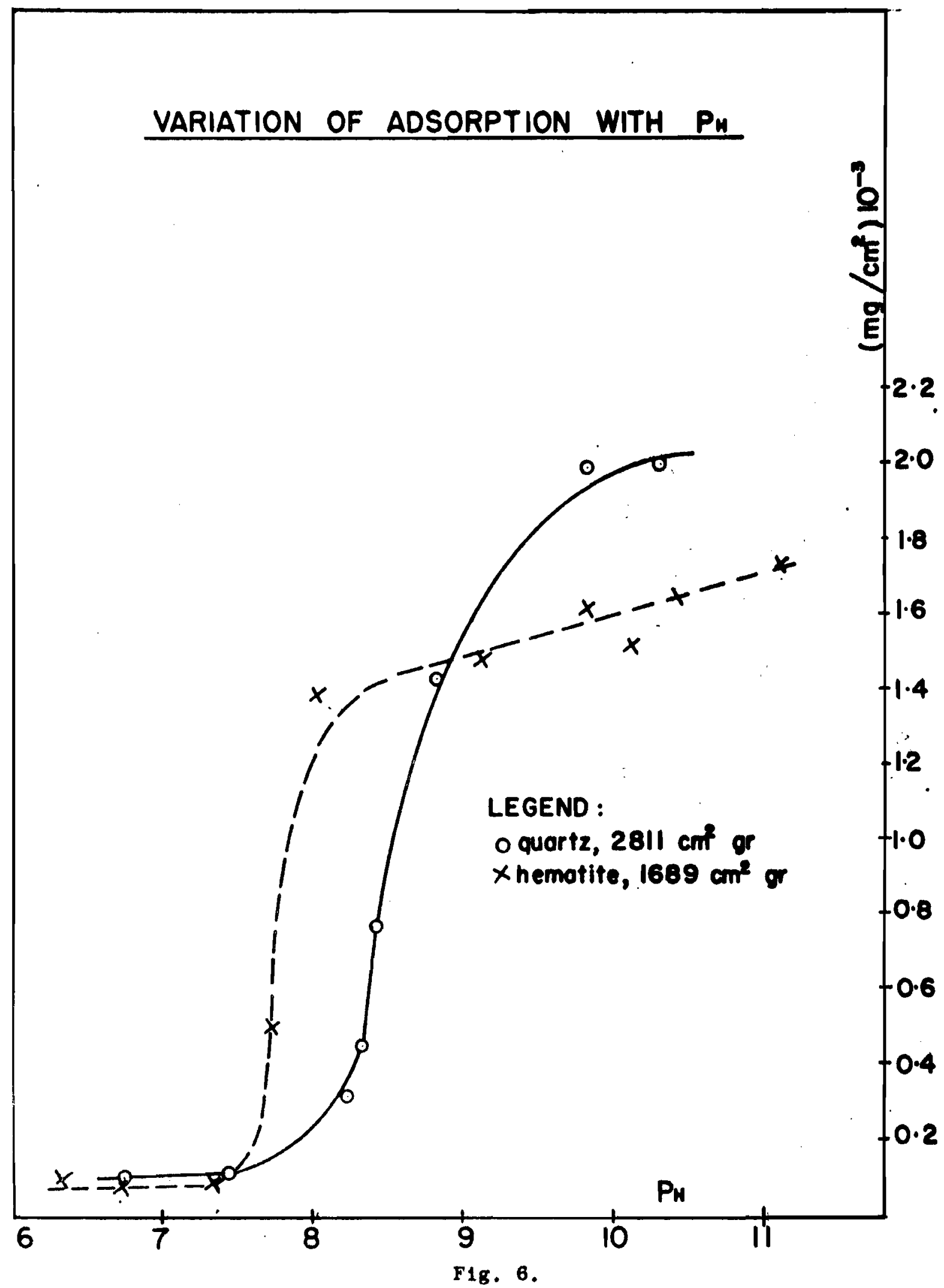


The two minerals follow a very similar pattern of changes with $\mathrm{pH}$ variations. A more detailed analysis, however, reveals the basic characteristic differences in these two adsorbents.

$\mathrm{Up}$ to the $\mathrm{pH}$ value of 7.5 the two isotherms remain parallel to each other and to the horizontal axis as well. This section is in the neighbourhood of the monolayer coverage. The unusual closeness of the two curves in this section again may be due to the slightly distorted readings caused by the colouring effect of hematite.

Above $\mathrm{pH} 7.5$ the isotherms show a rapid change in adsorption rate, and a more appreciable shift in the behaviour of the two mine rals. The isotherm representing hematite becomes very steep between 7.5 and 8. 5 and seems to reach a maximum value by the time the $\mathrm{SiO}_{2}$ isotherm begins to $\mathrm{rise}$ at $\mathrm{pH}$ 8.5. The latter curve reaches its peak at around $\mathrm{pH} 10$.

The general behaviour of silica and hematite surfaces seems to be supported by evidence gathered by J.G. Morrow (6) and P.L. de Bruyn (5). An adsorption isotherm presented by Morrow for the specular hematite-dodecylamine acetate system shows a very similar behaviour, considering that his reagent concentration is lower than that used in the tests of Fig. 6.

Values for silica as listed by de Bruyn (5) show that at 200 mg/liter dodecylamine concentration has a slope of zero, but he only investigated this up to $\mathrm{pH} 7$. This is practically identical to the trend shown on Fig. 6. 
Laboratory scale flotation test carried out in the laboratory of the Iron Ore Co. of Canada with the commercial equivalent of dehydroabietylamine showed that good selectivity, resulting in good grades and recovery, was achieved in the pH range of $8-10$. 


\section{SUMMARY}

1. Cationic collectors adsorb physically on the surface of oxides and the behaviour of dehydroabietylamine confirms this general statement.

2. Great similarity was observed between the adsorption properties of quartz and specular hematite in near neutral solutions with the adsorption rate becoming constant for hematite at approximately $200 \mathrm{mg} / \mathrm{liter}$ concentration.

3. A definite difference between the adsorption isotherms is created by altering the $\mathrm{pH}$ conditions of the aqueous solution. This results in an overall increase of the amounts adsorbed for both minerals but the absolute value of this increase for quartz is almost double that of the hematite adsorption.

4. The critical $\mathrm{pH}$ range for the highest rate adsorption of dehydroabietylamine on quartz was between $\mathrm{pH} 8.5$ and 10 and for hematite between 7.5 and $8.5 /$

5. Theorectical statements regarding the relationship between the surface charge and the adsorption characteristics of hematite and quartz are slightly contradicted by the adsorption results with dodecylamine acetate. Empirical flotation results seem to support the findings of this investigation. 


\section{SUGGESTIONS FOR FURTHER WORK}

Furthe $r$ investigations are recommended to compliment the results of this work. 1. Perhaps the most important of such work would be a series of flotation tests designed to cover a wide range of operating conditions, such as the collector concentration in the pulp - time and intensity of conditioning, strength of froth obtained and the most important the establishment of a selectivity factor of the collector at various $\mathrm{pH}$ values.

An expansion of this work could cover the effect of other modifying reagents on the flotation characteristics of dehydroabietylamine acetate. Such data could be very valuable in applying the results of fundamental research to more practical use.

The scale of the flotation testing is a matter of personal convenience. The Hallimond tube, or one of its modified forms is a frequently used instrument for such type of investigations. In other cases fritted glass filters can be converted into small flotation cells and immersed in constant temperature baths. The most important factor in getting up such equipment would be the degree of accuracy obtained in the tests and the maximum control over the variables affecting the process. 
2. More fundamental research should be concentrated on the nature of aqueous solutions of dehydroabietylamine acetate. This subject is very involved, mainly because the nature of solutions is not a finalized science.

Adsorption of dehydroabietylamine on solid surface will be greatly influenced by the state of the solute in the solutions. Determinations of critical micell concentration and the effect of micells present during adsorption would be an important factor to correlate. More work on the physicio-chemical nature of solutions would be an enormous help in explaining the mechanism of collection.

3. Temperature is one of the main variables of adsorption. It is of no less importance in liquid phase adsorption although it is hardly ever investigated in connection with the adsorption of cationic collectors.

The reason for such neglect of the subject is that flotation is usually a process carried out at ambient temperatures, whatever ii it happens to be. This is disturbingly simple on the surface, but one cannot forget that in many areas where flotation is practiced the water temperatures used in plants will vary considerably, - as much as $25^{\circ} \mathrm{F}$ with the seasons.

Some effort should, therefore, be spent to investigate the influence of solution temperature on collector adsorption over the range from $35^{\circ} \mathrm{F}$ to $100^{\circ} \mathrm{F}$. This temperature range would cover actual operating conditions and would not present any experimental difficulties. 
The results obtained from the investigation of temperature dependence of adsorption could lead to more theoretical work on the nature of adsorption. With the adsorption densities obtained for various temperatures the heats of adsorption could be calculated and a more distinctive line drawn between physical and chemical adsorption.

4. It is felt that the complex structure of dehydroabietylamine would warrant a study of this chemical to establish more about its chemical properties. Although a clear outline of such a study is very difficult to recommend, it should be a purely organic-chemical investigation aimed at the more subtle qualities of the amine such as detergency and local polarizations possibly occurring within the complex structure. 
R EFERENCES

(1) Iwasaki, Cooke, Colombo: Flotation characteristics of Goethite U.S. Bureau of Mines, 1960, Report of Inve stigations 5593 .

(2) Klassen \& Mokrousov: An intmoductionito the theory of flotation. Jutterworth, 1963 (Translation)

(3) Sherwood, R. J.: Private communications

(4) Gaudin \& Bloecher Jr.: Concerning the adsorption of Dodecylamine on Quartz. AIME TR. Vol. 187, 1955.

(5) P.L. deBruyn: Flotation of quartz by cationic collectors, Min. Eng. March 1955.

(6) Gaudin \& Morrow: Adsorption of dodecylammonium acetate on hematite and its flotation effect. AIMM, 1955.

Amine D \& Acetates: Hercules product information NS-283

Bishop, W.T.: Private communications

(9) Bruno \& Stenhager: Acta Chemica Scandinavica

13, p 832 (1959)

Suthe rland \& Wark: Principles of flotation, Australiasian Institute of Mining \& Metallurgy (1955)

Glembotski, Klassen, Plaksin: Flotatsia, Moscow 1961 GOS.IZDAT

Brunauer;, Gas and Vapour Adsorption, Vol. 1, Princeton Univ. Press. (1945)

Bokii, G. B.: Crystallochemistry, 1zd. MGU (1955)

Iwasaki, Cooke \& Kim: Some surface properties and flotation characterists of magnetite. AIME Transactions, Vol. 223, 1962 .

DeBruyn, P.L., Agar, G. E.: Surface chemistry of flotation froth flotation, 50th anniversary volume, AIME, 1962. 
(16) Parks, G.A. \& DeBruyn, P.L.: The zero point of charge of oxides, J. Phys. Chem. Vol. 66, 1962.

(17) Gaudin \& Fuenstenau: Quartz flotation with cationic collectors, Mining Eng. 958 No. 10, 1955.

(18) Zsigmondy \& Spear, E.G.: Chemistry of colloids;

John Wiley \& Sons, N.Y., 1917

(19) O'Connor, D.J. and Buchanan, A.S.: Australian J. Chem. 6, $278,1953$.

(20) O'Connor, Johansen, Buchanan: Trans. Faraday Soc. $52,229,1956$.

(21) Iler, R. K.: The colloid chemistry of silicates - Connell Univ. Press Ithaca, N. Y. 1955.

(22) Von W. Stöber: Ober flächenstructure und Adsorption Seingenschaften des $\mathrm{SiO}_{2}$, Univ. Göttingen.

(23) Joy, A.S., Watson, Di: Adsorption of collector and potentialdetermining ions in flotation of hematite with dodecylamine, Bulletin IMM, No. 687, 1964.

(24) Beckman Instruction Manual - 305-A

(25) Salman, T.: - B.E.T. measurements of fine powder surfaces, Private communications.

(26) Dana: Textbook of Mineralogy (16th edition, Hurlbut, John Wiley \& Sons.

(27) Brunauer, Emmett \& Teller: J. Am. Chem. Soc. 60.309, 1938.

(28) Lippens \& Hermans' Powder Met. No. 7, 1961. 
APPENIIX I. 
ANALYTICAL METHOD FOR THE DETERMINATION OF DEHYDROABIETYLAMINE ACETATE

To determine the adsorption of dehydroabietylamine acetate a rapld and accurate method was sought out. Colourimetric determination, developed by the Hercules Powder Co., was adopted as a sultable method for aqueous systems, containing from a few parts per million to several parts per million of dehydroabietylamine.

A number of instruments were available, but the spectrophotometer was chosen as the most accurate one.

\section{Chemistry of Determination}

The method is based upon the formation, in acidic aqueous solution, of a yellow coloured salt resulting from the reaction of the amine group of the dehydroabietylamine salt with the sulphuric acid form of bromophenol blue. This coloured salt, relatively insoluble in water, is extracted from the reaction mixture with chloroform. Excess unreactive bromophenol blue does not interfere. The colour density of the chloroform extract is pooportional to the amount of amine group present in the dehydroabietylamine, and can be measured visually or with photoelectric colourimeters or spectrophotometers.

Appropriate adjustment of sample size and reagent volumes enables application of this determination to a wide range of dehydroabietylamine concentrations. (Reference No. 8) 


\section{The Test Procedure:}

Range of determination 0-20 parts per million: The following procedure was designed for laboratory use in precise analysis of aqueous solution of dehydroabietylamine salts. A spectrophotometer, as the Beckman Model Du is used for colour measurement and gives an accuracy of 3 per cent of the amine product present.

\section{Procedure:}

Pipet into a $125-\mathrm{ml}$ separatory funnel $5.0 \mathrm{ml}$ of glacial acetic acid and $25.0 \mathrm{ml}$ of the sample solution. After mixing, allow to stand for $10 \mathrm{~min}$, , then pipet in $5.0 \mathrm{ml}$ of a bromphenol blue solution 10.04 pe $\mathrm{r}$ cent in water), and let stand another $10 \mathrm{~min}$. Then pipet in $25.0 \mathrm{ml}$ of chloroform, shake gently for $2 \mathrm{~min}$, and allow to stand until phases separate clearly. Withdraw part of the chloroform layer (lower) into 1-Cm spectrophotometer cells and measure the absorbance immediately against distilled water using a $0.08-\mathrm{mm}$ slit and $410 \mathrm{m \mu}$ wavelength. Duplicate tests should agree within 0.03 absorbance units for a relative accuracy of about 3 per cent.

A blank must be run on a sample of plain distilled water containing all the additives of the process except the amine. The same procedure applies here as for the original sample of solutions. The value of optical density obtained for this blank chloroform extract is subtracted from the optical density for the sample extract to obtain the corrected optical density. 
The corrected optical density or absorbance and the concentration in parts per million can be read from the caliuration curve, Fig. 7 obtained for dehydroabietylamine acetate.

It is necessary to run the se experiments in duplicate and have the readings remain within the range of 0.02 light absorbance units. This duplication is necessary because of the near impossibility of completely reproducing shaking operations.

$\underline{\text { Reagents: }}$

(1) Acetic acid glacial, c.p. (Baker's)

(2) Chloroform, c.p. (Baker's)

(3) Bromphenol blue (soluble form) (Lamotte Chemicals)

\section{Preparation of Solutions}

1. Standard Solution

Dissolve 1 gram of pure dehydroabietylamine acetate in distilled water and make volume up to exactly $100.0 \mathrm{ml}$. The concentration of this solution is 10,000 parts per million dehydroabietylamine acetate and it can be diluted to lower concentrations without development of turbidity. If an initial standard solution, having less than 10,000 parts per million, is prepared - cloudiness occurs.

2. Bromphenol Blue Solution: (0.04 per cent) Dissolve $40 \mathrm{mg}$ bromphenol blue in distilled wate $\mathrm{r}$ and make volume up to exactly $100 \mathrm{ml}$. Fresh solutions of bromphenol blue must be made up daily. In a limited 'study made on the stability of bromphenol 
blue solutions, it was found that an apparent decrease of about 10 per cent of the original concentration occurred after the first day. This decrease continued with time. Therefore, to avoid this difficulty it is suggested that fresh solution of this reagent be made up daily. Calibration of the Spectrophotometer By appropriate dilution of the above standard solution, prepareisolutions having concentrations of 5, 10, 15, 20 parts per million of dehydroabietylamine acetate. Submit each of the se solutions to the previously described procedure. Plot the average of optical densities, differing by less than 0.02 optical density units versus concentration in parts per million on linear paper as illustrated by Fig. 7 .

The optical density found for an unknown sample and the prepared calibration curve provide directly the effective concentration. 
SPECTROPHOTOMETRIC CALIBRATION CURVE FOR DEHYDROABIETYL AMINE ACETATE

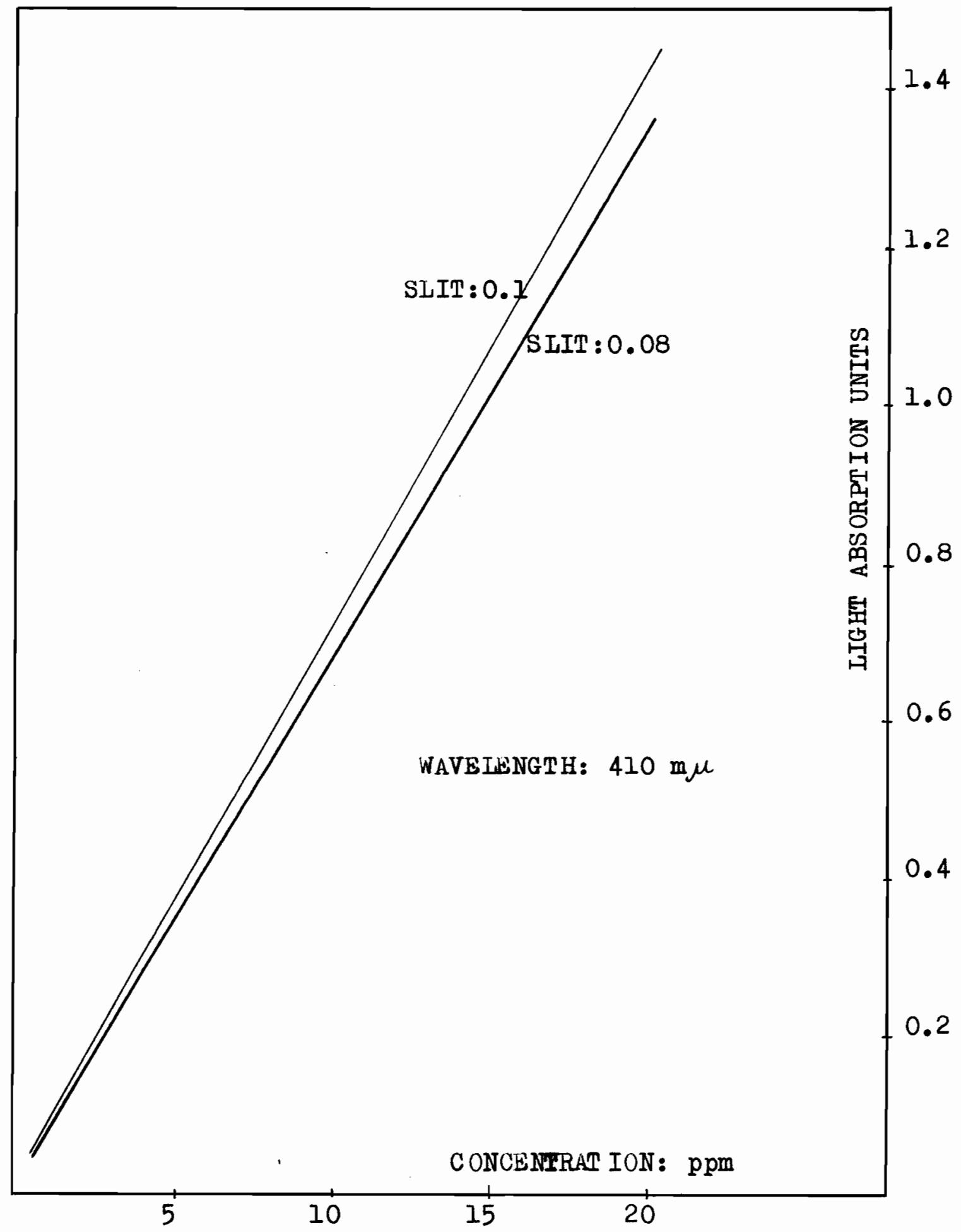


APPENDIX II. 


\section{SPECTROPHOTOMETRY}

Chemical substances, when dissolved in a solution, absorb light at certain wavelengths. The degree of absorption of light, or transmittance, depends upon the chemical identity of the substance.

This property can be used to identify chemical substances in solution with proper arrangement. The arrangement is the spectrophotometer. Essentially, it consists of a light source, containers for the samples of solutions and instruments that indicate the changes in the quantity of light transmitted.

The theory of spectrophotometry could be described by two basic laws:

1. Lambert's Law

2.. Beer's Law

Absorption spectrophotometry is a technique to determine the relationship between wavelength or frequency of radiation and its attenuation by absorption.

\section{Lambert's Law}

When monochromatic radiation passes through a homogeneous absorbing medium, the intensity of radiation is reduced by the same fractional unit in equal succeeding portions of its path. Assuming that the medium is made up of uniform layers, the following relationship can be written up for the light intensity at any part of the medium. 


$$
\frac{-\mathrm{dI}}{\mathrm{dl}}=\alpha \mathrm{I}
$$

Where: I - light intensity

$\alpha$ - fraction of reduction in intensity

1 - distance

Absorption coefficient $\quad \alpha=f(\lambda)$

$$
\text { and } \lambda=\text { wave length }
$$

Further developing this relationship:

$$
\begin{aligned}
& \ln \frac{\text { Io }}{E_{x}} \fallingdotseq \alpha x ; \text { or Ix }=\text { Io } \mathrm{e}^{-\alpha \mathrm{x}} \\
& \text { or } \\
& \begin{array}{l}
\log _{10} \quad \frac{\text { Io }}{\mathrm{Ix}}=\mathrm{KX} \quad \text { Where } \mathrm{K} \text { is the } \\
\text { extinction cocfficient } \\
\text { for monochøomatióc } \\
\text { radiations. }
\end{array}
\end{aligned}
$$

Beer's Law:

It applies when the absorbing medium is a substance in solution. In such a case the attenuation of radiation will depend on the concentration of the solution.

Under suitable conditions, the absorption by dissolved substances is closely proportional to the number of molecules of solute per unit volume of solution:

$$
\begin{aligned}
\alpha & =\mu \mathrm{c} \\
\text { Where: } \mathrm{c} & =\text { concentration } \\
\mu & =\begin{array}{l}
\text { absorption coefficient per unit } \\
\text { of concentration. }
\end{array}
\end{aligned}
$$


From this relationship it becomes evident that Lambert's and Beer's laws can be advantageously combined, whence we shall have:

$$
\ln \frac{\text { Io }}{\text { Ix }}=\mu \mathrm{C} x
$$

which represent the relationship between the intensity of light and concentration of solutions.

The following quantities are usually measured in spectrophotometry:

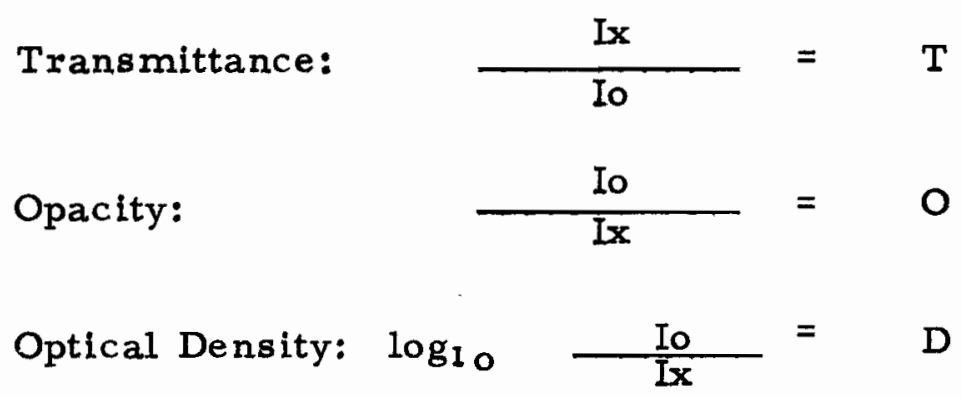

These are called the intensity variables. The other variable of the technique is: wavelength.

The Bechman Du spectrophotometer, utllizing the above principle is an accurate and fast means of determining the concentrations of dilute solutions.

Fig. 8 ilustrates the schematic arrangement of the optical system. Light from the Tungsten lamp is focused by the condensing mirror and directed in a beam to the diagonal slit entrance 
THE BECKMAN SPECTROPHOTOMETER OPTICAL SYSTEM OF MODEL DU.

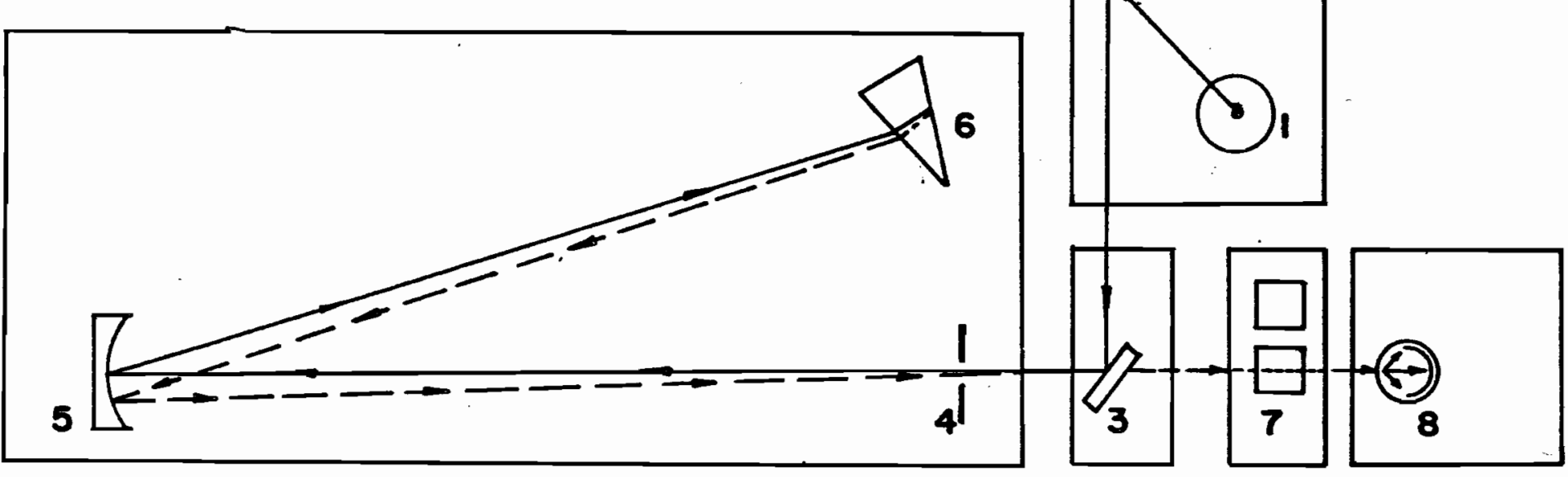

I Tungsten lamp

2 Condensing mirror

3 Diogonal slit entrance mirror

4 Slits

5 Collimating mirror

6 Quartz prism

7 Sample

8 Phototube

Fig. 8. 
mirror. The entrance mirror deflects the light through the entrance slit and into the monochromator to the collimating mirror. Light falling on the collimating mirror is rendered parallel and reflected to the quartz where it undergoes refraction. The back surface of the prism is aluminized so that the light refracted at the first surface is reflected back through the prism, undergoing further refraction as It emerges from the prism.

The deslred wavelength of light is selected by rotating the Wavelength Selector which adjusts the position of the prism. The spectrum is directed back to the collimating mirror which centers the chosen wavelength on the exit slit and sample. Light passing through the sample strikes the photo tube, causing a current gain. The current gain is amplified and registered on the null meter. (24). 
APPENDIX III. 


\section{GASEOUS PHASE ADSORPTION - GENERAL}

The term gaseous phase, aibso motion meptre tients the phenomenon according to which the concentration of gas molecules is always greater near the solid surface. It is due to a certain unbalance of forces of attraction at the surface. This unbalance of forces is partially restored by adsorption.

Since adsorption is a spontaneous process it will result in a decrease of free energy of the gas solid system. In addition to this, since the free gas molecules become adsorbed in layers the re is a loss of degrees of freedom and a decrease in entropy.

Therefore, from

$$
\Delta \mathrm{F}=\Delta \mathrm{H}-\mathrm{T} \Delta \mathrm{S} \text { it follow s }
$$

that the adsorption process must always be exothermic.

\section{MEASUREMENT OF THE SURFACE AREA BY THE B.E. T. METHOD}

It is quite easy to investigate the physical properties of large pieces of solid matter, but the same investigation becomes very complicated when the solids are in the submicroscopic size ranges.

Specific surface area is a very important parameter characterizing the physical and chemical properties of powders.

Definition: Specific surface area is the total accessible inner and outer surface area per unit weight of a material.

One property that depends greatly on specific surface $i$ is adsorption capacity. 
By making use of the B.E.T. apparatus it is possible to determine the specific surface area, to measure porosity and to determine pore size distribution.

When a gas or liquid comes in contact with a solid the tendency is such that a layer or layers of the gas or liquid will adhere to the solid surface. In cases where the layer is held onto the solids by weak forces like the Van der Waals forces we usually define this as physical adsorption.

The other possibility is when the forces are great enough to cause chemilicall reaction between the adhering layer and the solid surface. This is distinguished as chemical adsorption or chemisorption.

It is the phenomenon of physical adsorption which makes surface area calculations possible. Derivation of the B.E.T. Equation

Brunauer, Emmett and Teller derived a mathematical expression from the the rmodynamic considerations for the amount of gas adsorbed, based on the theory of multimolecular adsorption.

This theory is based on the assumption that before the surface is completely covered by a single layer of gas molecules, the formation of a second and subsequent layers has already started on top of the first one. 
As sumptions made in the derivation of the B.E.T.

equation:

(i) The heat of adsorption of the first layer

is independent of the degree of coverage.

(ii) The heat of adsorption of the second and subsequent layers is independent of the degree of coverage and ofcthe number of layers and it is equal to the heat of condensation.

In adsorption where no hinderance occurs during the process the following equation is valid:

$$
V a=\frac{C x}{(1-X)(1-X+C X)} V m
$$

where:

Va is the volume of the gas adsorbed at S.T.P. in $\mathrm{ml}$. /g. adsorbent.

$\mathrm{Vm}$ is the volume of the gas, $\mathrm{ml} / \mathrm{g}$. adsorbent at S.T.P., able to cover the whole surface of the adsorbent with a unimolecular layer of the gas.

$\mathrm{X}$ is the relative pressure, defined as the ratio between the actual pressure over the adsorbent (A) and the saturation pressure of the liquid adsorbate (Po).

C is a constant related to the difference between the heat of adsorption of the first layer and the heat of adsorption of the second and subsequent layers.

The measured quantities here, are:

$$
\begin{aligned}
& \mathrm{Va} ; \mathrm{X} ; \\
& \text { and } \mathrm{Vm} \text { is the quantity sought for the calculation }
\end{aligned}
$$

of the specific surface area: S. To evaluate Vim the previous equation :; is converted to: 


$$
\frac{x}{V a(1-x}=\frac{1}{V m \cdot C}+\frac{C-1}{V m \cdot C} x
$$

when :

$$
Y=\frac{X}{V a \cdot(1-X)}
$$

is plotted against $X$, the so called

B.E.T. plot is obtained. This is represented by a straight line defined by the equation:

$$
\underline{Y}=\mathbf{A}+\mathbf{B X}
$$

From the slope of the straight line:

$$
\begin{aligned}
& A=\frac{C-1}{V m \cdot C} \text {; and from the intercept: } \\
& B=\frac{1}{V m \cdot C}
\end{aligned}
$$

Now the monolayer capacity can be obtained as:

$$
V m=\frac{1}{A+B}
$$

To obtain the specific surface area from the calculated monolayer capacity it is necessary to know what portion of the surface area will be occupied by $1 \mathrm{ml}$ of gaseous adsorbate in a complete monolayer. Brunauer and Emmett assumed that the density of a substance adsorbed physically is equal to that of the substance at the same temperature.

Also assuming spherical molecules for the substance in closed packing a volume for nitrogen was obtained to be $4.37 \mathrm{~m}^{2} / \mathrm{ml}$. The range of application for the B.E.T. equation is stated to be between: 0.05 and 0.25 relative pressure values. When the pressure is below this range, assumption 1); that is the heat of adsorption is negligible, is not valid any more for certain active spots on the surface. 
On the other hand, when the pressure ratios exceed 0.25

the influence of the difference between the heats of adsorption of the second and the subsequent layers becomes too great. As it was stated at the beginning the possibility of the adsorption of an infinite number of layers is necessary for the application of the B.E.T. equation. This condition is somewhat restricted when the pores are very narrow. Certain investigators showed that if the maximum number of possible layers is greater than 3 , it can still be applied. However, to determine the surface area when the pores are even smaller, would require a very elaborate trial and error method. It should be noted again that although the B.E.T. apparatus is generally used for surface area measurements, it can also be used for the determination of complete adsorption and desorption isotherm. For this purpose it is necessary to know the total amount of gas adsorbed at different gas pressures.

\section{DESCRIPTION OF THE APPARATUS:}

Although there are many variations of the B.E.T. apparatus to suit some specific type of determination, the basic components are still the same. These are:

(i) The vacuum system 
Pressure $P_{2}$ is determined after equilibrium is reached again. Now, a value for the total volume Vt can be calculated from:

$$
V t \div \frac{\Delta \ddot{V}}{\Delta P} P_{2}
$$

where: $\Delta \mathrm{P}=\mathrm{P}_{2}-\mathrm{P} 1$

Calibration should be carried out with ascending and descending mercury level in the burette and the average $x$ values used for greater accuracy.

(iii) Specific surface area measurement

The type of gas used for surface area measurement will depend on the type of material used as a sample. For example nitrogen can be used for samples whose specific surface areas fall between the range:

$$
1 \text { to } 2,000 \mathrm{~m}^{2} / \mathrm{gram}
$$

When the specific surface area of a sample falls below $1 \mathrm{~m}^{2} / \mathrm{gram}$, using $\mathrm{N}_{2}$ an error will be encountered because $\mathrm{Va}$ is much smaller than the volume of gas in the sample tube. In such cases Krypton should be used as a satisfactory adsorbate, because the correction for unadsorbed gas is low due to the low saturation pressure of liquid Krypton at temperatures below the boiling point. The changes necessitated by using Krypton instead of nitrogen are relatively small. The purpose of using Krypton is to measure small specific surface areas, but the method is also applicable to large surface areas if small enough samples are prepared. Therefore, the ultimate advantage of the Krypton B.E.T. system is that it can operate effectively from very low areas to very high areas; that is to say from:

$$
200 \mathrm{~cm}^{2} / \mathrm{gram} \text { to } 2,000 \mathrm{~m}^{2} / \mathrm{gram}
$$

(iv) Calculations

The total volume of Krypton Vt at any equilibrium pressure is the sum of all Krypton additions made previously. The volume adsorbed $\mathrm{Va}$ is obtained by subtracting the volume of gas in the McLeod system $\mathrm{Vmc}$ and the volume of gas in the free space surrounding the sample and not adsorbed, Vs, from the total volume of gas present. 
(ii) The gas system. The gas is used in a purifled state for the adsorption.

(iii) The measuring system. This consists of the following components:

(a) the sample tube,

(b) a U tube to serve as a cold reservoir or trap where the mercury vapors might interact with the sample,

(c) a burette with calibrated volumes, enclosed in a jacket for temperature control if necessary,

(d) a manometer,

(e) a McLeod gauge for pressure measurements up to $5 \mathrm{~mm} \mathrm{Hg}$,

(f) hellum storage vessel for callbration purposes.

\section{EXPERIMENTAL METHOD}

(i) Preparation of the sample.

Often the sample should be desorbed at high vacuum and at approximately $300^{\circ} \mathrm{C}$. The gene ral rule here is that the highest pposible temperature and the lowest possible pressure be used to effect good desorbing.

(ii) Calibration.

The adsorption measurements are done at very low pressure while the rest of the apparatus is at room temperature. The sample tube is immersed into liquid nitrogen. After the thermal equllibrium has been reached, the pressure of the gas, $P_{1}$ is read from the manometer. After this the mercury level in the burette is ralsed to the next mark, decreasing the volume by a known: $\Delta \mathrm{V}$ 
That is: $\mathrm{Va}=\mathrm{Vt}-\mathrm{Vmc}-\mathrm{Vs}$

$\mathrm{Vt}$ and Vmc can be obtained from:

$$
\frac{P_{1} \cdot V_{1}}{T_{1}}=\frac{P_{2} \cdot V_{2}}{T_{2}}
$$

Where: Subscript 2) represents standard and Subscript 1) operating conditions.

Vs is calculated from:

$$
V s=(P c) \cdot(F s)
$$
Where: $P_{c}-$ is the equilibrium pressure,
corrected to $0^{\circ} \mathrm{C}$

Fs - is the free space factor

The following diagrams represent the general layout of the B.E.T. apparatus, the vapour pressure curves for nitrogen and Krypton and the curves for surface area determinations of quartz and hematite. 


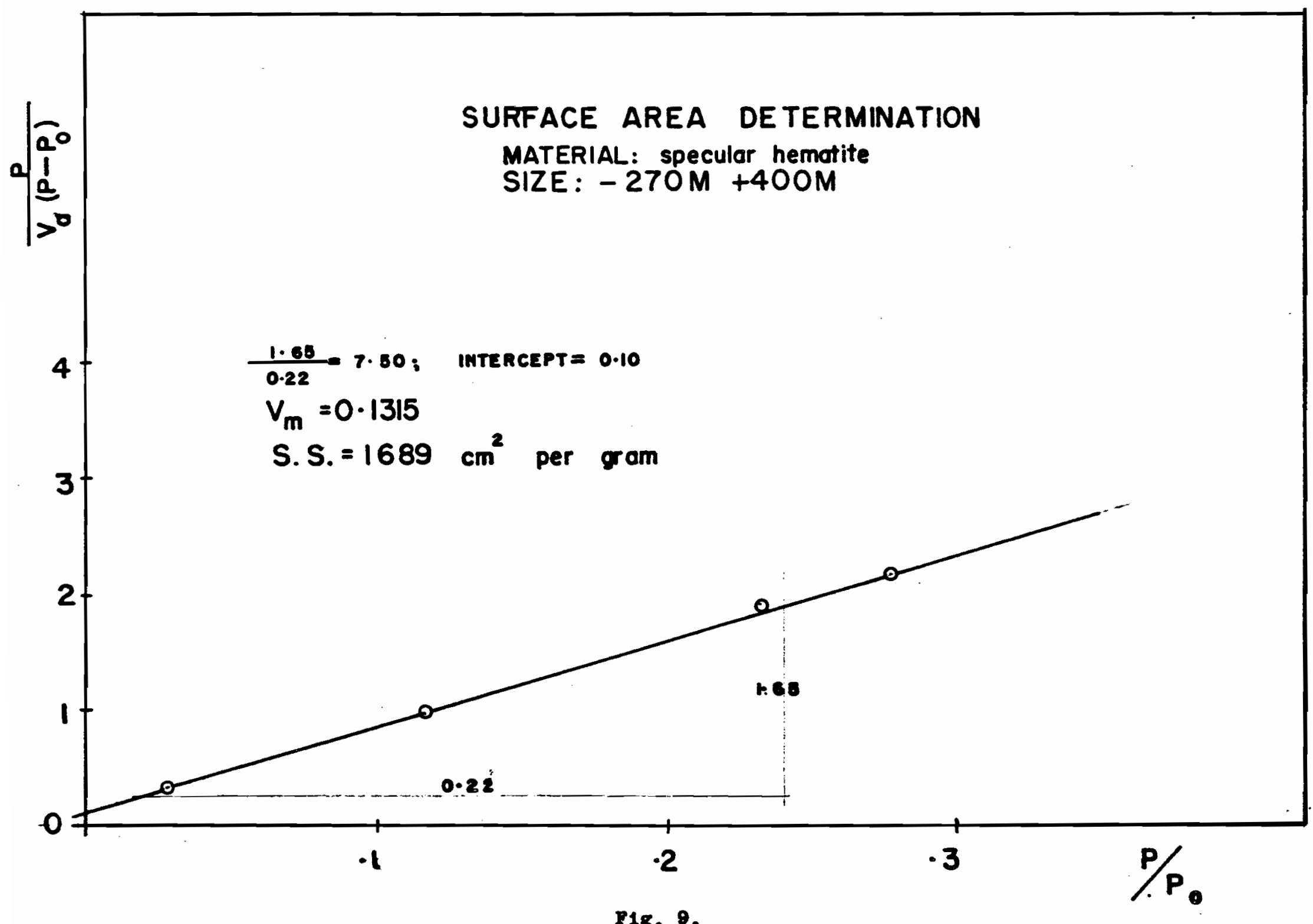




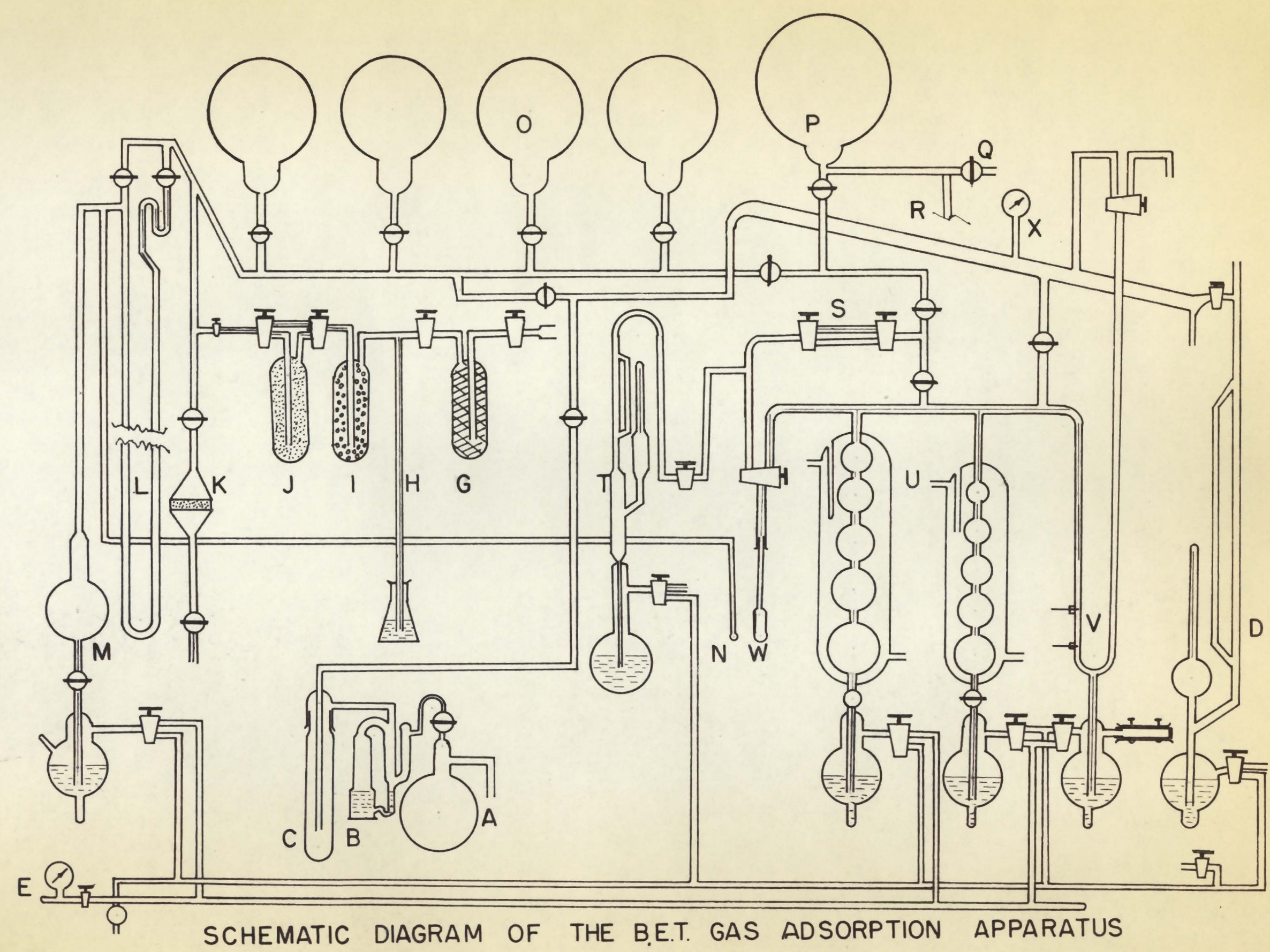




\section{MAIN PARTS OF GAS ADSORPTION APPARATUS}
A Mechanical pump
B - Mercury diffusion pump
C - Trap
D. McLeod gauge
$E$ - Compressed air
F - Mechanical pump
G_ Trap (Reduced copper gouze, heating coil over trap to give $350^{\circ} \mathrm{C}$ )
H_Borometric leg for relief of over pressure
1 - Trop (Glass beods)
$J$ - Trap (_18_28 mesh activated charcoal to remove impurities from He )
K - Drying tube
$L$ - Manometer of gas thermometer system
$M$ - Gas holder, to compress gos to produce liquid-vopor equilibrium in the temperature bulb at operating temperatures

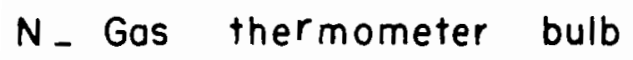

O_ Gas reservoirs

P_ Gas reservoir ( 5 liter copocity, for Krypton storage )

Q_ Purified Krypton source

$R$ - Borometric leg for relief of over pressure - Krypton

S. Calibroted doser for Krypton gas

$T_{\text {- Calibroted McLeod gauge for Krypton system ( } \mathrm{O}-10 \mathrm{~mm} ., \mathrm{Hg} .)}$

U_ Gos burettes

$V$ - Manometer with fine adjustment control and mogic eye indicator

W- Sample tube

$X_{\text {- Pironi gauge }}$ 


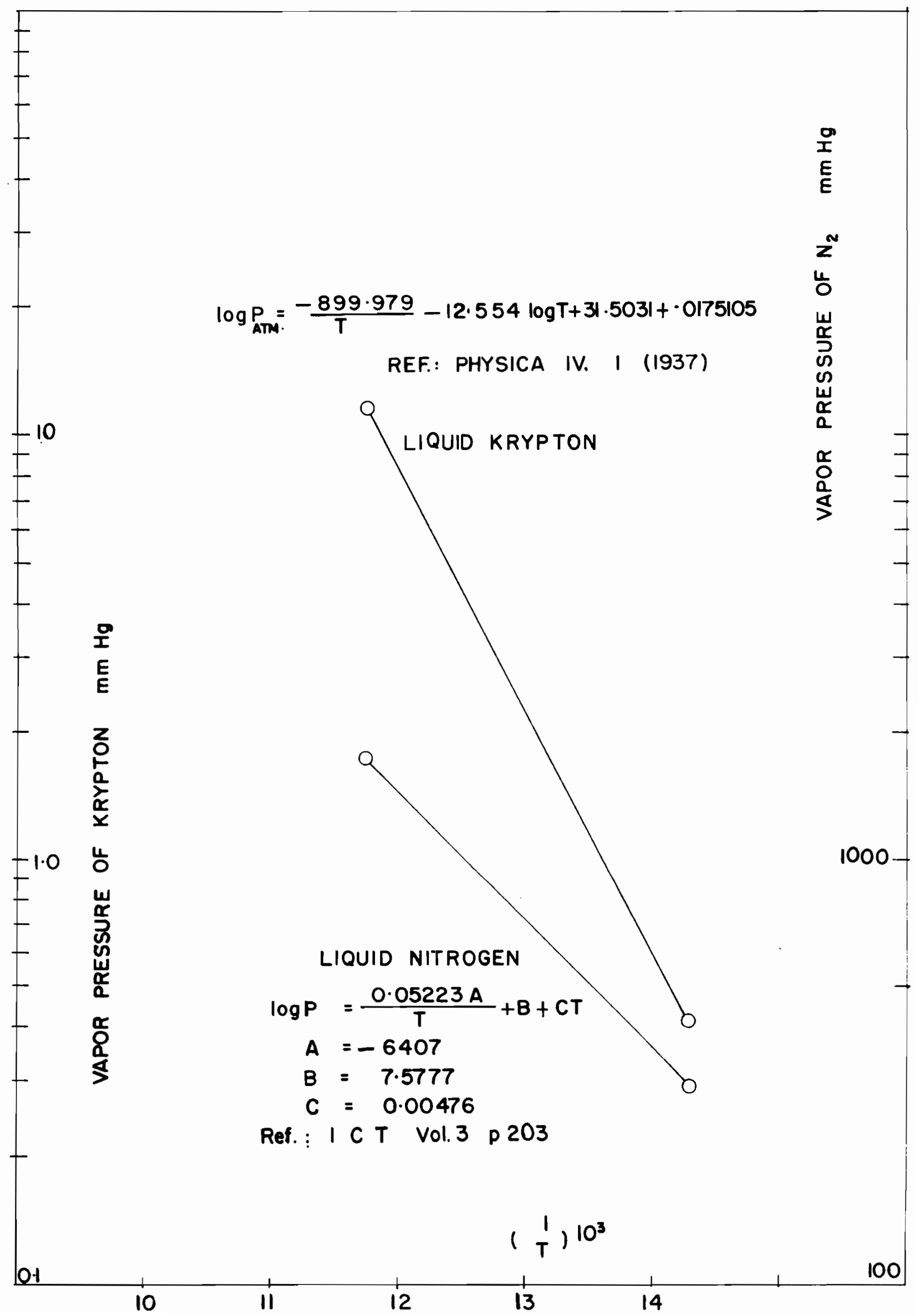

